\title{
A Natural Resource Theory of U.S. Crop Insurance Contract Choice
}

\author{
Xiaodong Du, David A. Hennessy, Hongli Feng
}

\begin{abstract}
A large variety of subsidized crop insurance products are available to U.S. crop growers. Distinct and perhaps puzzling patterns in the choices of insurance products and coverage levels can be discerned. Where production conditions are better and yields are less risky then $(a)$ higher insurance coverage levels are chosen; and (b) revenue insurance is preferred over yield insurance. Also, $(c)$ the extent of preference for revenue insurance is stronger in more productive areas. Assuming, as many do, that growers seek to maximize subsidy transfers, point $(a)$ can be explained by the interaction between yield technology and natural resource endowments. Points $(b)$ and $(c)$ can be explained by location in conjunction with the "natural hedge" and a contract design bias in how revenue insurance guarantees are computed. Empirical study of Risk Management Agency data on corn, soybean, and wheat yields, and insurance contract choices lend support to our model inferences.
\end{abstract}

Key words: agricultural policy, contract choice, crop insurance, land use, yield risk measurement.

JEL codes: Q15, Q18, Q24.

The U.S. federal crop insurance program provides agricultural producers with subsidized insurance against crop losses. The main contractual forms are yield insurance and revenue insurance. Yield insurance involves choosing a fraction of historical average yield to be indemnified at a given price, while revenue insurance involves choosing a fraction of the imputed expected revenue to be indemnified. The level of revenue guarantee can be chosen based on known futures prices when signing a contract, or can vary with the price at harvest by paying a higher premium. Revenue insurance is the most popular among the classes of insurance contracts offered by the Federal Crop Insurance Corporation (FCIC). As of 2012, the revenue insurance contract revenue protection (RP) accounts for about $70 \%$ of FCIC liabilities (USDA, RMA 2012). For both yield and revenue insurance, the choice of coverage level

Xiaodong $\mathrm{Du}$ is an assistant professor, Agricultural and Applied Economics, University of Wisconsin-Madison. David A. Hennessy and Hongli Feng are, respectively, professor and adjunct assistant professor, Department of Economics, Iowa State University. determines the premium subsidy rate, where the rate falls as coverage level increases. Program parameters are provided in table 1, taken from Shields (2010).

Although crop insurance premiums are required to be set at actuarially fair rates, opportunities to choose coverage level, as well as between yield and revenue insurance contracts create regional differences in subsidies paid per expected bushel covered for a given crop. Crop insurance indemnities have tended to be concentrated in regions with unfavorable growing conditions, for example the Great Plains states. Moreover, the historical distribution of insured acres at various locations reveals some interesting patterns in contract choice. For example, the share of insured corn acres under revenue insurance is higher in Iowa than in Kansas, while Iowa corn also tends to be under higher coverage levels than elsewhere (Babcock 2011).

An extensive body of literature has examined crop insurance choices, including participation, insurance products (e.g., yield versus revenue insurance) and coverage level, and has linked these choices to various factors. Results in Smith and Baquet (1996) indicate that, conditional on participation, 
Table 1. Crop Insurance Premium Subsidies on Yield- and Revenue-Based Products (Government-Paid Portion of Premium as a Fraction of Total Premium)

\begin{tabular}{lccccccccc}
\hline Coverage level $\phi$ & CAT & 0.5 & 0.55 & 0.6 & 0.65 & 0.7 & 0.75 & 0.8 & 0.85 \\
Subsidy rate $s$ & 1.0 & 0.67 & 0.64 & 0.64 & 0.59 & 0.59 & 0.55 & 0.48 & 0.38 \\
Effective Government Schedule & & & & & & & \\
Coverage level $\phi$ & CAT & 0.5 & 0.6 & 0.7 & 0.75 & 0.8 & 0.85 \\
Subsidy rate $s$ & 1.0 & 0.67 & 0.64 & 0.59 & 0.55 & 0.48 & 0.38 & \\
Log subsidy, $\ln (s)$ & 0.0 & -0.400 & -0.446 & -0.528 & -0.598 & -0.734 & -0.968 & \\
\hline
\end{tabular}

Source: Table 1 of Shields (2010).

Note: The schedule of subsidy rates listed here applies to insurance policies using basic and optional units. The schedule for policies using enterprise units and whole farm units are different and not shown here.

growers with positive expected returns from crop insurance choose different coverage levels than those with negative expected returns. Utilizing a mail survey and a twostep procedure, Sherrick et al. (2004) first analyze growers' decisions over whether to insure, and then examine growers' decisions between hail, yield, and revenue insurance. Yield/revenue insurance use is found to be significantly affected by the probability of insurance payments, expansion intentions, importance of risk management, as well as other variables. A recent study by Barnett and Coble (2012) concludes that regional differences in crop insurance purchases can be largely attributed to different crop revenue risks resulting from yield variability and the correlation between yield and price. In particular, Barnett and Coble note that, when compared to Southern corn, soybean and wheat producers, Midwestern farmers tend to purchase more revenue insurance. This is surprising because the Midwest is where the majority of U.S. production of these crops originates, and supply in these areas has a greater influence on price than does supply in peripheral regions. Thus, national prices tend to be more negatively correlated with Midwestern yields than with yields from elsewhere. This would suggest that revenue is more stable, revenue insurance premiums are smaller, revenue insurance dollar subsidies are smaller, and yield insurance might be a comparatively better approach for securing subsidy transfers.

The present study posits a theory of how natural resources affect insurance contract choice. The theory assumes that crop insurance premiums are actuarially fair and that risk-neutral growers seek to maximize the extent of crop insurance subsidy transfers given the schedule of contract parameters available. $^{1,2}$ We suggest that the interaction between yield/revenue risk and natural resources (i.e., the stochastic technology) can explain why higher levels of protection are chosen in more productive cropping areas. We then work through why revenue insurance might and might not be a better vehicle for obtaining premium transfers. There is not a clear-cut answer, but a strongly negative correlation between price and yield (as in the Corn Belt) would favor the use of yield insurance. However, features of insurance contract design favor the use of revenue insurance, and especially so toward the geographic center of a crop's production region. To assess these inferences, we investigate the linkage between crop insurance contract choices and geography, where the latter is represented by a set of exogenous factors, including soil quality, precipitation, growing season temperature, geographic location, and distance to the center of crop production. Risk Management Agency data on corn, soybean and wheat insurance contract choices lend support to our model.

\footnotetext{
${ }^{1}$ Regarding actuarial fairness, note that administrative costs are borne by the government so that unsubsidized premium should equal expected payout for the considered contracts. Although it may go too far to assert that this equality presently applies, loss ratios have improved over time (Glauber 2013) as a result of the USDA Risk Management Agency's longstanding goal of securing program soundness. See, for example, the program review in Coble et al. (2010).

${ }^{2}$ It has been maintained by many that crop insurance choice is being driven by premium subsidies, not by risk management (Goodwin 2001, Babcock 2011, Sumner and Zulauf 2012). We do not claim that growers are risk-neutral. We do intend to show that the risk aversion assumption is not necessary to explain many crop insurance contract choices. If risk aversion also explains these choices, then further empirical work would be needed to identify the origin of demand. If risk aversion were to suggest that choices should have been different, then our empirical work would provide evidence in favor of the hypothesis that transfers motivate contract choices rather than risk management concerns. But these matters go beyond the present work's scope.
} 
The paper proceeds as follows. We first discuss some relevant details regarding U.S. crop insurance markets. We then introduce theoretical models that seek to shed light on preferences regarding extent of coverage and form of insurance contract. Our inferences depend on the nature of the stochastic production technology. We follow the theoretical section by summarizing our basic findings in a set of propositions. We then discuss the employed data, develop empirical strategies, and present our estimates. We conclude by discussing the estimation results and presenting some concluding comments.

\section{Crop Insurance Markets}

Although the specifics of crop insurance rate setting are somewhat involved (Coble et al. 2010), the general format is as follows. Catastrophic insurance for yield losses greater than $50 \%$ is provided to growers where the assumed price is low and the only charge is an administrative fee. Our concern in this paper is with buy-up coverage beyond this level. The government sets buy-up coverage premium rates, while insurance companies market contracts, collect premia, and make some underwriting choices. For the stochastic underwritten item, $U$, be it yield or revenue, let the institutional estimate of mean value be $\bar{U}$. If the coverage level is $\phi$, then the indemnity is $\max [\phi \bar{U}-U, 0]$. With $E[\cdot]$ as the expectation operator, then an actuarially fair premium would be $E[\max (\phi \bar{U}-U, 0)]$. The subsidy rate is proportional to premium, so if $s$ is the subsidy rate, then the subsidy's dollar value is Subsidy $=s E[\max (\phi \bar{U}-U, 0)]$. So the producer pays $(1-s) E[\max (\phi \bar{U}-U, 0)]$ to the crop insurance company and the government transfers the subsidy directly to the insurance companies. ${ }^{3}$

Subsidies are homogeneous of degree 1 in value. That is, when the value of the underwritten scales, say from $U$ to $\lambda U$, with $\lambda \neq 1$, then one would expect the value of $\bar{U}$ to change to $\lambda \bar{U}$. Since $s E[\max (\phi \lambda \bar{U}-$ $\lambda U, 0)]=\lambda s E[\max (\phi \bar{U}-U, 0)]=\lambda$ Subsidy, it follows that the dollar subsidy is likely to scale proportionately. Thus, be it yield or revenue insurance, the absolute value

\footnotetext{
3 The government also covers other insurance costs, but these are not germane to our study.
}

of the subsidy offered will be larger when commodity prices are higher, as from 2007-2013 compared with 1997-2006. ${ }^{4}$

Revenue insurance is a comparatively recent innovation. While federal intervention in crop insurance markets extends back to the 1930s, a variety of direct and indirect subsidies were provided only on yield insurance contracts. The program remained very limited in scope until the Federal Crop Insurance Act of 1980, which expanded the breadth of regions and crops covered, but continued to offer only multi-peril yield insurance contracts. Between 1980 and 2013, farm bills and insurance-specific acts further expanded the extent of subsidies and variety of contracts that can be subsidized. In particular, the Crop Insurance Reform Act of 1994 allowed for subsidized Revenue Insurance contracts, and these became available in 1996.

A 1998 adjustment shifted revenue product premium subsidies to the same proportional footing as yield insurance, rather than having it capped at the subsidy amount available for crop insurance contracts. Revenue insurance is better targeted at grower risk concerns (Hennessy, Babcock, and Hayes 1997). Furthermore, revenue insurance is generally more expensive than yield insurance, even at comparable coverage levels. In light of the proportional nature of subsidies as laid out above, it is not surprising that by 2011 about 5 acres in 6 covered by crop insurance were under revenue specification. ${ }^{5}$ Overall, federal budget costs for all forms of crop insurance had expanded to average $\$ 5.5$ billion/year in 2010 and 2011, and have been projected to average $\$ 9$ billion/year from 2012 to 2022 (Congressional Budget Office 2012). As of 2012, crop insurance premium subsidies at the unit level are as given in table 1, while yields and revenues that are covered at a more aggregate level (e.g., whole farm or based on district-level yields) are provided with more generous subsidy rates.

Several additional comments are warranted regarding revenue insurance. It generally comes in two forms, where both guarantee and evaluated revenue are keyed off futures contract prices (Edwards 2011).

\footnotetext{
${ }^{4}$ How subsidies are affected by coverage level $\phi$ is more involved. We will show that effective coverage level for revenue insurance contracts has a geographic dimension to it.

5 Babcock, A. 2011. The Revenue Insurance Boondoggle: A Taxpayer-Paid Windfall for Industry. Environmental Working Group. http://static.ewg.org/pdf/Crop_Insurance.pdf.
} 
The most direct form is referred to as revenue protection with harvest price exclusion (RPHPE). In RPHPE, an estimate of expected yield is arrived at, which we call $\bar{y}$, and this estimate is multiplied by the pre-planting crop futures price for the first new crop contract. For example, with corn in 2013, the February 2013 average price for the December 2013 delivery contract would be used to establish the price component of the revenue guarantee. If we refer to this average price as $\bar{F}_{\text {Dec,Feb }}$, then the guarantee upon taking out coverage level $\phi$ would be $\phi \bar{F}_{\text {Dec,Feb }} \bar{y}$. With $y$ as actual harvest yield and $F_{\text {Dec,Dec }}$ as the harvest futures price, the indemnity is:

$$
I^{\mathrm{RPHPE}}=\max \left(\phi \bar{F}_{\mathrm{Dec}, \mathrm{Feb}} \bar{y}-y F_{\mathrm{Dec}, \mathrm{Dec}}, 0\right) .
$$

The other form of RP, which is the one most commonly purchased, includes a harvest price protection provision. This allows for a price reset when assessing the revenue protected in the event that futures prices increase between the time of initial price-setting and harvest. The price is set at $\max \left(\bar{F}_{\text {Dec,Feb }}, F_{\text {Dec,Dec }}\right)$, so that revenue protection without a harvest price exclusion offers the indemnity:

$$
\begin{aligned}
I^{\mathrm{RP}}= & \max \left[\phi \max \left(\bar{F}_{\mathrm{Dec}, \mathrm{Feb}}, F_{\mathrm{Dec}, \mathrm{Dec}}\right) \bar{y}\right. \\
& \left.-y F_{\text {Dec,Dec }}, 0\right] .
\end{aligned}
$$

This specification is more popular in part because the price option provides the grower with an additional revenue stream to support cash market forward sales contracts in the event that the grower has a yield shortfall and harvest prices are high. Furthermore, the price option increases the expected indemnity. As $\max \left(\bar{F}_{\text {Dec,Feb }}, F_{\text {Dec,Dec }}\right) \geq F_{\text {Dec,Dec }}$ $\forall F_{\text {Dec,Dec }} \in[0, \infty)$ and $\max (x, 0)$ is an increasing function of $x$, it follows that $I^{\mathrm{RP}} \geq$ $I^{\mathrm{RPHPE}} \forall F_{\text {Dec,Dec }} \in[0, \infty)$, and so the subsidy is larger under RP than under RPHPE.

Note that for both RPHPE and RP, the revenue guarantee are formed as the product of expected yield and some form of expected price. That is, the posited revenue expectation is not of form $E[F y]$, with $F$ representing the harvest futures price. Rather, it is of form $E[F] E[y]$ where $E[F] E[y] \neq E[F y]$ whenever price and yield are correlated.

\section{Basic Model}

We motivate our analysis by first studying yield insurance contracts. Let $p$ be the insured price, $\mu(v)$ be mean yield, and $\phi \mu(v)$ be guaranteed yield where $\phi \in[0,1]$. Here, $v$ is a vector of conditioners, such as land capability class and climate measures, so that mean yield depends on soils and climate. In the empirical analysis, this vector of geographic conditioners will be observed at the county level. For the sake of clarity in exposition we will assume that the ordinates in $v$ are ordered such that larger is better, e.g., better land or climate.

Stochastic yield is given by the Just-Pope technology:

$$
y=\mu(v)+\sigma(v) \varepsilon,
$$

where $\varepsilon$ has distribution $G(\varepsilon):[\underline{\varepsilon}, \bar{\varepsilon}] \rightarrow[0,1]$ such that the density $g(\varepsilon)$ exists over the domain. For $E[\cdot]$ the expectation operator over this distribution, impose $E[\varepsilon]=0$ so that $\sigma(v)$ is a scaling factor that depends on geographic attributes. The rationale for this location-scale representation of the yield distribution is that it can be estimated by using the Just-Pope methodology (see Just and Pope (1979) and later works that use it).

Let $\psi(v) \equiv(\phi-1) / \tau(v)<0$, where $\tau(v)=$ $\sigma(v) / \mu(v)$ is the coefficient of variation. With the subscript indicating the derivative, we note that:

$$
\begin{gathered}
\tau_{v}(v)=\left[\mu(v) \sigma_{v}(v)-\mu_{v}(v) \sigma(v)\right] /[\mu(v)]^{2} \\
\stackrel{\operatorname{sign}}{=} d \ln [\sigma(v)] / d v-d \ln [\mu(v)] / d v
\end{gathered}
$$

If the coefficient of variation is increasing in the value of $v$, then the value of $\psi(v)$ becomes less negative with an increase in the value of $v$. The value of $\psi(v)$ is of interest because the crop insurance indemnity may be written as:

$$
\begin{aligned}
h(\varepsilon) & \equiv p \max [\phi \mu(v)-y, 0] \\
& \equiv p \sigma(v) \max [\psi(v)-\varepsilon, 0] .
\end{aligned}
$$

With $w \equiv E[h(\varepsilon)]$, expected indemnity is:

$$
\begin{aligned}
w= & p \sigma(v) E\{\max [\psi(v)-\varepsilon, 0]\} \\
= & p \psi(v) \sigma(v) G[\psi(v)] \\
& -p \sigma(v) \int_{\underline{\varepsilon}}^{\psi(v)} \varepsilon d G(\varepsilon) .
\end{aligned}
$$


An integration by parts establishes that $\int_{\varepsilon}^{\psi(v)} \varepsilon d G(\varepsilon)=\psi(v) G[\psi(v)]-\int_{\underline{\varepsilon}}^{\psi(v)} G(\varepsilon) d \varepsilon$, so that

$$
\begin{aligned}
w & =p \sigma(v) J[\psi(v)] ; \\
J[\psi(v)] & =\int_{\underline{\varepsilon}}^{\psi(v)} G(\varepsilon) d \varepsilon .
\end{aligned}
$$

Assuming the insurance policy is actuarially fair, then total premium equals expected indemnity. Suppose that a subsidy at rate $100 s \%$ is provided on the premium. With $B$ as the government (expected) budget allocation, then the expected cost to the government is: $B \equiv s w \equiv s p \sigma(v) J[\psi(v)]$.

For a fixed budget we may write:

$$
\begin{aligned}
\ln (s) \equiv & \ln (B / p)-\ln [\sigma(v)] \\
& -\ln (J[\psi(v)]),
\end{aligned}
$$

which we also write implicitly as $H[\phi, \ln (s)$, $B, v]=0$. Here, the grower can choose over some point set $(\phi, s) \in K$ that is laid down by policy makers, that is, the table 1 schedule.

\section{Preferences}

The grower's assumed goal is to maximize the expected budget transfer obtained, where the grower is held to be risk-neutral. Thus, a grower with geographic conditioners $v$ chooses $(\phi, s) \in K$ to maximize the expected size of budget transfer $B$. Put differently,

$$
\max _{(\phi, s) \mid v} \operatorname{sp\sigma } \sigma(v) J[\psi(v)] \quad \text { s.t. } \quad(\phi, s) \in K
$$

where $\mid v$ signifies that couple $(\phi, s) \in K$ is chosen conditional on $v$.

Problem (7) holds that the expected income transfer can be viewed as separable from other income sources when making contract choices. Three assumptions underlie this specification. One regards the set of $v$ under scrutiny, another relates to the interactions between contract choice and production decisions, and the third concerns risk-neutrality.

Regarding the first assumption, our interest is in the choice of $(\phi, s)$ from $K$ as the values of $v$ change. Note that the $v$ considered, which includes land quality, climate variables and location, might generally be viewed as exogenous to the decision process. However, one should recognize a selection issue in that the availability of subsidies and shape of $(\phi, s) \in K$ may determine the land that is cropped. The concern is not likely to be of much import in the central Corn Belt, but may be significant in more marginal growing areas (Claassen et al. 2011).

For the second assumption, it is assumed that insurance contract choice does not affect intensive marginal farming practices, that is, moral hazard is not a significant issue. Were moral hazard a concern, then fully understanding how contract choices might vary across space would require a proper accounting of indirect effects involving how geography, input choices and contract choices interact. For example, yield sensitivity to fertilizer might vary across regions so that geographic differences in moral hazard opportunities arise. The FCIC programs seek to reduce moral hazard by basing guarantees on historical yield performance, so that a grower is automatically disciplined for moral hazard behavior. However, this safeguard may have limited impact in some regions, as opportunities exist to detach actual production history from recorded production history. For example, producers can request that yield in a given year be replaced by $60 \%$ of the county's transition yield when computing recorded "actual" production history, or APH (Edwards 2012). In addition, when establishing an APH, a floor is placed on transition APH relative to the county's transition yield, and this further decouples a land unit's recorded APH from historical performance. Finally, many land units have APH histories of much less than 10 crop years. This situation suggests that some units that are building toward an APH that is less desirable than their transition APH are liquidated before facing the yield guarantee consequences of earlier yield realizations.

Regarding risk-neutrality, one set of justifications for this assumption is as follows. A variety of risk management opportunities are presently available to U.S. crop growers. While futures and options are generally not used directly by growers, commodity merchandizers use these markets to lay off risk arising from a variety of popular price risk management opportunities that are offered to growers. Growers can also use crop diversification to reduce profit variability in any one year and use savings to self-insure across years. Other government policies are available, such as countercyclical payments. Further, Briggeman (2011) reports that $90 \%$ of farm household income 


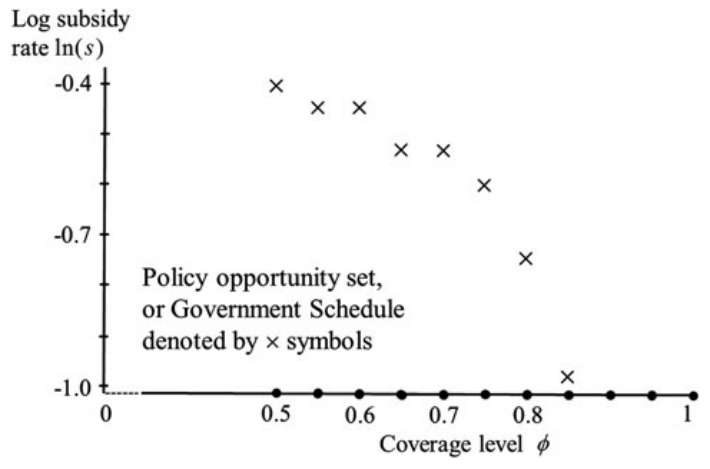

Figure 1. Actual government schedule for coverage level and subsidy rate

comes from off-farm activities. However, our view regarding these three concerns about objective function (7) is not that they are irrelevant. Rather, our perspective is that a pure transfer theory can explain much of how geography affects crop insurance contract choices. Consequently, a comprehensive understanding of the role for geography in insurance contract demand should accommodate how geography affects risk, information asymmetries, and the expected value of direct transfers.

We seek to understand the implications of imposing the table 1 schedule across all land units and all commodities. Figure 1 depicts the schedule in log subsidy form, consistent with equation (6). This might be viewed as the policy opportunity set. There are two flat regions at $\phi=[0.55,0.60]$ and $\phi=[0.65,0.70]$. A flat part is likely dominated by the rightmost point on the line segment. For example, coverage level 0.6 is likely preferred to coverage level 0.55 , given that the same insurance subsidy rate is offered. Figure 2 removes the dominated segments to obtain the Effective Government Schedule (EGS); it also provides the directions of preference on the part of growers seeking to maximize expected transfers, namely for larger yield guarantee $\phi$ and for larger log subsidy rate $\ln (s)$. The EGS is given in the lower panel of table 1 , and we refer to the set of points therein as set $\hat{K}$.

Figure 2 also provides possible transfer indifference curves (TIC) for EGS points in $(\phi, \ln (s))$ space. Here, TIC means that for a given specified point from the EGS the expected transfer is identified, for example at $B^{\prime}$. Then $\phi$ and $\ln (s)$ values are allowed to vary off the schedule point, but such that transfer $B^{\prime}$ remains fixed, that is, relation (6) must be satisfied for $B^{\prime}$. The grower can

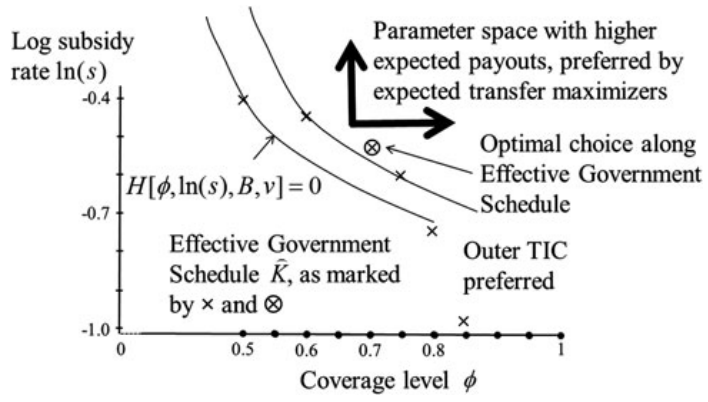

Figure 2. Preference over effective government schedule for coverage level and subsidy rate

choose the value of $(\phi, \ln (s)) \in \widehat{K}$ that maximizes the expected value of transfer $B$. In figure 2 it is clear that neither of the graphed TIC maximizes the expected transfer. The grower would maximize by moving out a bit further to choose the TIC that passes through $(0.7,-0.528)$, labeled as $\otimes$. Of the two TIC that are graphed the outer TIC, through $(\phi, \ln (s))=(0.6,-0.446)$, is preferred over the inner curve through $(\phi, \ln (s))=(0.5,-0.4)$. But that is an artifact of the distribution at issue, as given by the assumed general distribution $G(\varepsilon)$ and the grower's particular $y=\mu(v)+\sigma(v) \varepsilon$.

In figure 2 the choice problem is somewhat regular because we characterize the TIC as being convex. To determine whether this is a valid assumption, we inquire into the shape of the TIC in $(\phi, \ln (s))$ parameter space. The first- and second-differentials are:

$$
\begin{aligned}
\left.\frac{d \ln (s)}{d \phi}\right|_{\text {eqn. (6) }} & =-\frac{1}{\tau(v)} \frac{d \ln [J(\psi)]}{d \psi}<0 ; \\
\left.\frac{d^{2} \ln (s)}{d \phi^{2}}\right|_{\text {eqn. (6) }} & =-\frac{1}{[\tau(v)]^{2}} \frac{d^{2} \ln [J(\psi)]}{d \psi^{2}} .
\end{aligned}
$$

Function $J(\psi)$ is said to be log-concave in $\psi$ whenever $d^{2} \ln [J(\psi)] / d \psi^{2}<0$ over its domain, that is, whenever $g(\psi) \int_{\underline{\varepsilon}}^{\psi} G(\varepsilon) d \varepsilon<$ $[G(\psi)]^{2}$. As shown in Bagnoli and Bergstrom (2005), a wide variety of density functions are log-concave. Indeed, a log-concave density function suffices, but is not necessary, for the corresponding function $J(\psi)=\int_{\underline{\varepsilon}}^{\psi} G(\varepsilon) d \varepsilon$ to be log-concave. Together with $(\overline{8})$, we then have:

Proposition 1. If $J(\psi)$ is log-concave in $\psi$, then the TIC is decreasing and convex. 
Thus, it is reasonable to assume that the TIC is convex. We next turn to the role of geography in the analysis.

\section{Role of Geography}

Here we determine how the slope $[d \ln (s) /$ $d \phi]\left.\right|_{\text {eqn. (6) }}$ changes with the value of $v$, for this will relate how geography can affect preferences along the government schedule. Upon differentiating $\left.[d \ln (s) / d \phi]\right|_{\text {eqn. (6) }}$ in (8) with respect to $v$, we then simplify:

$$
\begin{aligned}
& \left.\frac{d^{2} \ln (s)}{d \phi d v}\right|_{\text {eqn. (6) }} \\
& =\left\{\frac{d \ln [J(\psi)]}{d \psi}-(1-\phi) \frac{d^{2} \ln [J(\psi)]}{d \psi^{2}}\right\} \\
& \quad \times \frac{\tau_{v}(v)}{[\tau(v)]^{2}} .
\end{aligned}
$$

Thus, we have:

Proposition 2. Suppose that $J(\psi)$ is logconcave in $\psi$. An increase in $v$ then makes trade-off $\left.[d \ln (s) / d \phi]\right|_{\text {eqn. (6) }}$ more negatively (resp., positively) sloped whenever coefficient of variation $\tau(v)$ is decreasing (resp., increasing) in $v$. In the case of $\tau_{v}(v) \leq 0$ (resp., $\tau_{v}(v) \geq 0$ ), then a larger (resp., smaller) $\phi$ value and smaller (resp., larger) $\ln (s)$ value will be chosen along the Government schedule offered to the grower.

Figure 3 depicts the case where $\tau_{v}(v) \leq 0$, $v<v^{\prime}$ and $J(\psi)$ is log-concave. Land with higher $v$ values will receive high yield guarantees and a low subsidy. The TIC tilts

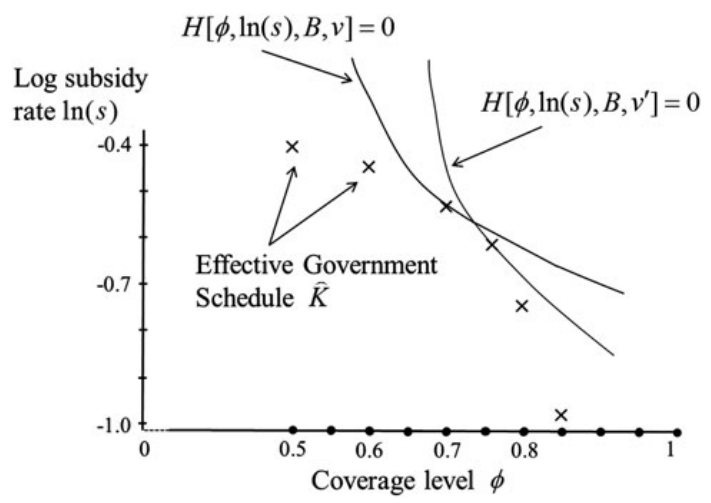

Figure 3. Change in insurance schedule choice when $v$ increases and the coefficient of variation is decreasing in $v$ clockwise as $v$ increases. In sum, the premises of log-concavity and uniform sign on $\tau_{v}(v)$ are testable while the consequences for contract choices over EGS points are also testable. Proposition 2 provides us with one of the items for empirical inquiry.

\section{Revenue or Yield Insurance}

We turn now to the choice between revenue and yield insurance. The observations we make regard the nature of the price-yield covariance, as well as how revenue insurance contracts are designed. We commence with the benchmark case where price and yield are independent.

\section{Price-Yield Independence}

With expected price $\bar{p}$ as the price election under yield insurance, then the yield indemnity is $\bar{p} \max [\phi \bar{y}-y, 0] \equiv \max [\phi \bar{p} \bar{y}-$ $\bar{p} y, 0]$, whereas the revenue indemnity is $\max [\phi \bar{p} \bar{y}-p y, 0]$. A well-known finding in martingale theory is that $E\{\max [\phi \bar{p} \bar{y}-p y, 0]\}$ $\geq E\{\max [\phi \bar{p} \bar{y}-\bar{p} y, 0]\}$ when random variables $p$ and $y$ are independent (see Shaked and Shanthikumar 2007). Thus, we have:

Proposition 3. If price and yield are independent, then the grower seeking to maximize expected transfers under proportional subsidies will prefer revenue insurance with payout $\max [\phi \bar{p} \bar{y}-p y, 0]$ over yield insurance with payout $\bar{p} \max [\phi \bar{y}-y, 0]$.

While this may appear to be intuitive, let us consider now the case where a dependent relationship exists between price and yield. Suppose that $p \equiv v / y$, where $v$ is a positive constant as in Hennessy (2002). In this extreme case there is no farm-level idiosyncratic risk while the demand function has unit elasticity. Then, although both price and yield are random, revenue is not. The actuarially fair premium on a revenue insurance contract is zero and there is no subsidy transfer. However, a yield insurance contract would carry a positive premium and would thus generate a positive subsidy transfer. When contrasted with the inference in Proposition 3, this example clarifies that whether yield or revenue insurance involves greater transfers depends on the market context. 


\section{Price-Yield Correlation Issues}

We return to the RPHPE specification (1), which essentially presumes that mean revenue is $\bar{p} \bar{y}$ and not $\bar{p} \bar{y}+\operatorname{cov}(p, y)$. With $R$ as revenue, the indemnity when the revenue expectation is formed correctly less that when the expectation is formed incorrectly, as in RPHPE, is:

$$
\begin{aligned}
& \Delta[\operatorname{cov}(p, y)] \\
& =\max [\phi \bar{p} \bar{y}+\phi \operatorname{cov}(p, y)-R, 0] \\
& \quad-\max [\phi \bar{p} \bar{y}-R, 0] .
\end{aligned}
$$

The key point to note is that when $\operatorname{cov}(p, y)=0$, then $\Delta[\operatorname{cov}(p, y)]=0$, whereas when $\operatorname{cov}(p, y)<0$, then $\Delta[\operatorname{cov}(p, y)]<0$.

Proposition 4. Consider any revenue distribution such that $\operatorname{cov}(p, y)<0$. Then the expected indemnity under the RPHPE contract is larger than when expected revenue is correctly formed.

The proposition conveys that there is an upward bias in the magnitude of revenue insurance indemnities in more centrally located production regions, where $\operatorname{cov}(p, y)$ is more negative. To be clear, this does not mean that the premiums are actuarially unfair. The premiums are set equal to the expected payout, but at any given value of nominal coverage level $\phi$, the true fraction of expected revenue that is covered is too high. This observation relates to table 1 in that under RPHPE, when $\operatorname{cov}(p, y)<0$, then the true fraction of expected revenue that is covered is higher than as given in table 1. Taking a ratio, we have $\phi \bar{p} \bar{y} /[\phi \bar{p} \bar{y}+\phi \operatorname{cov}(p, y)]=$ $1 /[1+\operatorname{cov}(p / \bar{p}, y / \bar{y})]>1$ so that the true fraction of expected revenue that is covered is not $\phi$, but rather $\phi /[1+\operatorname{cov}(p / \bar{p}, y / \bar{y})]>\phi$.

We now refer to

$$
\begin{aligned}
\mathcal{L} & =\frac{\phi}{1+\operatorname{cov}(p / \bar{p}, y / \bar{y})}-\phi \\
& =-\frac{\phi \operatorname{cov}(p / \bar{p}, y / \bar{y})}{1+\operatorname{cov}(p / \bar{p}, y / \bar{y})}
\end{aligned}
$$

as the change in true coverage due to the expectations formation bias. It is positive whenever the covariance is negative, while $d \mathcal{L} / d \phi$ has the sign of $\mathcal{L}$. Thus, whenever

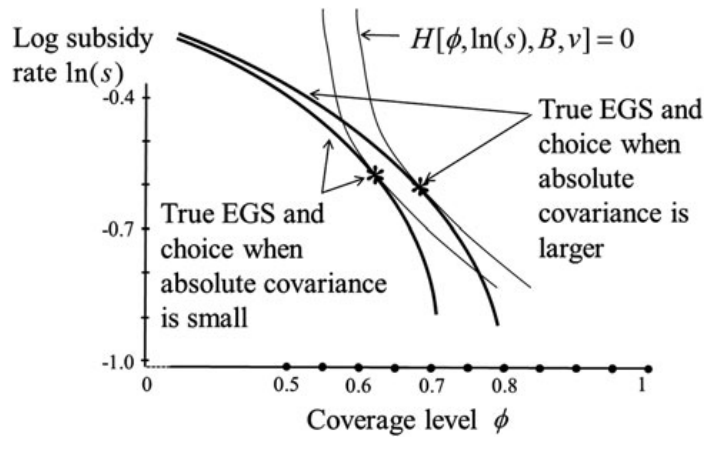

Figure 4. Effect of negative price-yield
covariance on true revenue coverage,
together with coverage choice implicaitons

$\operatorname{cov}(p / \bar{p}, y / \bar{y})<0$, then the magnitude of the rightward map in coverage, true less nominal, increases as the coverage level increases. The marginal incentive to choose $\phi=\phi^{\prime \prime}$ rather than $\phi=\phi^{\prime}$, with $\phi^{\prime \prime}>\phi^{\prime}$, is positive when $\operatorname{cov}(p / \bar{p}, y / \bar{y})<0$. Figure 4 illustrates this with a stylized continuous representation of the EGS; more centrally located growers might respond by taking out higher coverage levels. In addition, this bias in coverage levels does not arise for yield insurance.

Proposition 5. Under RPHPE the preferred coverage level increases as the price-yield covariance decreases.

Improper expectation formation might motivate a comparative preference for revenue insurance over yield insurance in more centrally located regions, as well as higher choices of $\phi$ given the revenue product choice.

With regard to RP as given in (2), that is, including the harvest price option, we have noted that the price option will drive the premium up so that the expected transfer will be larger under it than under a contract with a harvest price exclusion. Among revenue insurance contracts it should be more strongly preferred, and that is generally the case. How preference should change as distance from geographic region changes is more involved. We write the actual harvest price as $p$ and refer to the earlier price as $\hat{p}$ so that the payment is $I^{\mathrm{RP}}=\max [\phi \max (\hat{p}, p) \bar{y}-y p, 0]$. Suppose that the unconditional price distribution is $L(p)$, while the price-conditioned yield distribution is $Q(y \mid p)$. Expected indemnity is then: 


$$
\begin{aligned}
E\left[I^{R P}\right]= & \underbrace{\int_{\hat{p}}^{\infty} p\left(\int_{0}^{\infty} \max [\phi \bar{y}-y, 0] d Q(y \mid p)\right) d L(p)}_{\text {Yield insurance, random price }} \\
& +\underbrace{\int_{0}^{\hat{p}} \int_{0}^{\infty} \max [\phi \hat{p} \bar{y}-y p, 0] d Q(y \mid p) d L(p)}_{\text {Improperly formed revenue insurance }} .
\end{aligned}
$$

From integration-by-parts, $\int_{0}^{\infty} \max [\phi \bar{y}-$ $y, 0] d Q(y \mid p)=\int_{0}^{\phi \bar{y}} Q(y \mid p) d y, \quad$ and becomes

$$
\begin{aligned}
E\left[I^{R P}\right]= & \int_{\hat{p}}^{\infty} p \int_{0}^{\phi \bar{y}} Q(y \mid p) d y d L(p) \\
& +\int_{0}^{\hat{p}} \int_{0}^{\infty} \max [\phi \hat{p} \bar{y}-y p, 0] \\
& \times d Q(y \mid p) d L(p) .
\end{aligned}
$$

Now where $d Q(y \mid p) / d p \geq 0$, then an increase in market price would be associated with an increase in the probability of low yield outcomes, or $d \int_{0}^{\phi \bar{y}} Q(y \mid p) d y / d p \geq 0$. When $d \int_{0}^{\phi \bar{y}} Q(y \mid p) d y / d p \geq 0$, then the GrussCebycev covariance inequality ensures that: underpinning revenue insurance, where expected revenue insurance indemnities fall when price risks offset yield risks to stabilize revenue.

The role of storage also matters when assessing RP. It is likely that when harvest price is low, then national yields are high and storage is high. Because storage is used to smooth inventories over time, $\operatorname{cov}(p, y \mid p \leq \hat{p})$ is likely to be less negative than $\operatorname{cov}(p, y \mid p>\hat{p})$, where in the latter situation low inventories mean extreme price sensitivity to yield shocks (Deaton and Laroque 1992). Given (13)-(14), the likely comparatively strong and negative price-yield correlation over $p \in(\hat{p}, \infty)$ that will arise in centrally located production areas will make this form of revenue insurance more attractive in these regions than elsewhere. Thus, when compared with yield insurance, the

$$
\begin{aligned}
E\left[I^{R P}\right] & \geq \frac{\int_{\hat{p}}^{\infty} p d L(p) \int_{\hat{p}}^{\infty} \int_{0}^{\phi \bar{y}} Q(y \mid p) d y d L(p)}{1-L(\hat{p})}+\int_{0}^{\hat{p}} \int_{0}^{\infty} \max [\phi \hat{p} \bar{y}-y p, 0] d Q(y \mid p) d L(p) \\
& =E[p \mid p>\hat{p}] \int_{\hat{p}}^{\infty} \int_{0}^{\phi \bar{y}} Q(y \mid p) d y d L(p)+\int_{0}^{\hat{p}} \int_{0}^{\infty} \max [\phi \hat{p} \bar{y}-y p, 0] d Q(y \mid p) d L(p) .
\end{aligned}
$$

In light of (14), one can infer that RP is more beneficial when price and yield tend to move in opposite directions than when they do not. This is because any yield shortfall will likely be accompanied by an upward price reset. This inference is interesting, as it is quite the reverse of the intuition
RP version of revenue insurance is likely to weigh further in favor of revenue insurance for more centrally located areas.

We use an example to summarize and compare the effects identified above:

Example 1: Consider the standard twovariable Bernoulli distribution as follows:

$$
(p, y)=\left\{\begin{array}{l}
(2,2) \text { with probability } \pi_{h, h}=0.25(1+\rho) \\
(2,0) \text { with probability } \pi_{h, l}=0.25(1-\rho) \\
(1,2) \text { with probability } \pi_{l, h}=0.25(1-\rho) \\
(1,0) \text { with probability } \pi_{l, l}=0.25(1+\rho)
\end{array}\right.
$$


Thus, prices can be high or low, and yield can be good or disastrous. Parameter $\rho \in[-1,1]$ represents the price-yield correlation, with $\rho<0$ reflecting $\operatorname{cov}(p, y)<0$ and $d \operatorname{cov}(p, y) / d \rho>0$. We will study how $\rho$ affects payments under the various contracts.

The unconditional mean price is $\bar{p}=1.5$, while the unconditional mean yield is $\bar{y}=1$. Mean revenue is $\bar{R}=1.5+0.5 \rho \in[1,2]$, and expected indemnities are as follows: only for $\rho>1 / 3$ that losses from having low prices when yields are low offset the price option provision benefits. Given the above, it is no surprise that more centrally located producers opt for RP.

In summary, proposition 3 holds that when price and yield are independent, and expected revenue formation accounts for price-yield correlation, then revenue insurance should carry the larger premium.
Yield ins. :

Revenue ins. with proper expectation formation :

Revenue ins. with RPHPE expectation formation :

Revenue ins. with RP expectation formation :

$$
E\left[I^{Y}\right]=0.75 \phi
$$$$
E\left[I^{\text {Proper }}\right]=(0.75+0.25 \rho) \phi ;
$$$$
E\left[I^{\mathrm{RPHPE}}\right]=0.75 \phi \text {; }
$$$$
E\left[I^{\mathrm{RP}}\right]=(0.875-0.125 \rho) \phi .
$$

Of course correlation is irrelevant under yield insurance. Under revenue insurance with proper expectation formation, a negative price-yield correlation reduces the expected indemnity so that $\left(E\left[I^{\text {Proper }}\right]-E\left[I^{Y}\right]\right) \rho=0.25$ $\rho^{2} \phi>0$, as required from propositions 3 and 4 . Now compare this with payment when revenue insurance is improperly formed according to RPHPE. In this example, improper expectation formation has completely offset the natural hedge so that yield insurance and revenue insurance have the same premium, and consequently the same expected transfer. This is due to the simplicity of the state space. More generally, one would expect a critical correlation parameter value $\hat{\rho}<0$ below (above) which yield (revenue) insurance has the higher expected indemnity. However, $E\left[I^{\mathrm{RPHPE}}\right] \geq E\left[I^{\text {Proper }}\right]$ whenever $\rho \leq 0$, that is, RPHPE secures larger expected subsidy transfers in more central production regions. Note too that the RP contract satisfies $E\left[I^{\mathrm{RP}}\right] \geq 0.75 \phi=E\left[I^{Y}\right]=E\left[I^{\mathrm{RPHPE}}\right]$. This is due to the expensive price option feature embedded in RP.

More interesting is the comparison between RP and properly formed revenue insurance, and it provides the example's main point. As $E\left[I^{\mathrm{RP}}\right]-E\left[I^{\text {Proper }}\right]=$ $0.125 \phi-0.375 \rho \phi$, whenever $\rho \leq 1 / 3$, then $E\left[I^{\mathrm{RP}}\right] \geq E\left[I^{\text {Proper }}\right]$. Properly formed revenue insurance becomes more expensive as the price-yield correlation $\rho$ increases from -1 through 1 . However, under RP the expected indemnity declines as $\rho$ increases from -1 through 1 . This is the point made in inequality (14). Indeed, when comparing $\mathrm{RP}$ with proper revenue insurance, it is
But when price and yield are negatively correlated and expected revenue formation accounts for price-yield correlation, then the reverse may apply so that yield insurance would carry the higher expected transfer. Proposition 4 points out the following for the HPE revenue insurance contract, which does not account for price-yield correlation when forming expected revenue. Given a negative price-yield correlation, the de facto coverage level is likely higher for revenue insurance than for yield insurance, so that subsidies are comparatively more generous for revenue insurance. This tilt in subsidy generosity is absent where the price-yield correlation is zero. Overall, and upon generalizing beyond example 1 , the impact on comparative demand for revenue insurance over yield insurance when being in a more centrally located production region is unclear. However, proposition 5 shows that if one chooses revenue insurance, then one should probably take out a higher coverage level.

\section{Data}

In this study we employ the crop insurance contract choice data for the 2011 crop year as obtained from the Summary of Business (SOB) Reports and Data maintained by the Risk Management Agency of the U.S. Department of Agriculture (RMA/USDA). ${ }^{6}$

\footnotetext{
${ }^{6}$ Data can be downloaded from http://www.rma.usda.gov/ data/sob/scc/index.html.
} 
Table 2. Insurance Plans for Corn, Soybean, and Wheat in the SOB Report of 2011

\begin{tabular}{lcc}
\hline $\begin{array}{l}\text { Crop } \\
\text { Crop }\end{array}$ & $\begin{array}{c}\text { Yield Insurance Products } \\
\text { (plan code in RMA's SOB report) }\end{array}$ & $\begin{array}{c}\text { Revenue Insurance Products } \\
\text { (plan code in RMA's SOB report) }\end{array}$ \\
\hline Corn & 01,04 & $02,03,05,06$ \\
Soybean & 01,04 & $02,03,05,06$ \\
Wheat & 01,04 & $02,03,05,06$ \\
\hline
\end{tabular}

Insurance Plan Code, Abbreviation, and Name

\begin{tabular}{ll}
\hline 01 & YP (Yield Protection) \\
02 & RP (Revenue Protection) \\
03 & RPHPE (Revenue Protection with Harvest Price Exclusion) \\
04 & GRP (Group Risk Plan) \\
05 & GRIPH (Group Risk Income Protection - Harvest Revenue Option) \\
06 & GRIP (Group Risk Income Protection) \\
\hline
\end{tabular}

The dataset contains county-level crop insurance purchase information, including insured acreage under a variety of insurance contracts and coverage levels for the major crops across the United States. ${ }^{7}$ In this paper, however, we focus only on corn, soybean, and wheat.

Revenue and yield insurance products offered in 2011 are the same for the three crops and are summarized in table $2 .{ }^{8}$ The yield-based insurance plans that trigger payoffs based on yield shortfalls include Yield Protection (YP) and Group Risk Plan (GRP). The revenue-based insurance plans that protect against revenue shortfalls include Revenue Protection (RP), Revenue Protection with Harvest Price Exclusion (RPHPE), Group Risk Income Protection (GRIP) and Group Risk Income Protection - Harvest Revenue Option (GRIPH). ${ }^{9}$ For the analysis on coverage-level choices, we aggregate the acres insured under certain coverage levels across all insurance plans. Similarly, acres covered in revenue or yield insurance plans across all coverage levels are aggregated for the analysis of contract choice between revenue and yield insurance. We focus on 13 states in the Midwest and Great Plains

\footnotetext{
${ }^{7}$ Detailed dataset variable lists are at http://www.rma.usda.gov/ data/sob/scc/1980-2012.pdf.

${ }^{8}$ Catastrophic (CAT) crop insurance coverage is excluded from the sample and we focus only on buy-up coverage. We exclude CAT because it is very different in form from buy-up choices. Aside from an administrative fee, the entire premium is covered by the federal government, while the price used is also much less generous.

${ }^{9}$ Crop insurance policy offerings were consolidated in the 2011 crop year. Basically, YP has replaced Actual Production History (APH), RP has replaced Crop Revenue Coverage (CRC) and Revenue Assurance (RA), while RPHPE has replaced Income Protection (IP) and Indexed Income Protection (IIP). Empirical results from using 2010 data are available upon request.
}

regions (IL, IN, IA, KS, MI, MN, MO, NE, $\mathrm{ND}, \mathrm{OH}, \mathrm{OK}, \mathrm{SD}$, and WI) for corn and soybean, and on 11 states for wheat (we omit IA and WI from the abovementioned 13 states).

To summarize the insurance coverage-level choices, we calculate the acreage-weighted coverage level (WCL) for an individual county $i, W C L_{i}=\sum_{j \in Z} s_{j} C L_{j}$, where $s_{j}$ is the acreage share of certain coverage level $C L_{j}$, and $Z$ is the set of available coverage choices. WCLs for revenue and yield insurance are calculated separately. Figure 5 presents the revenue and yield insurance acreage-weighted coverage levels for corn, soybean, and wheat across the studied counties. For corn and soybean, crop producers located in the central Corn Belt counties with comparatively favorable growing conditions tend to choose insurance plans with relatively high coverage levels, and thus these counties show comparatively high WCLs. The spatial pattern for wheat WCLs is not as clear as those for corn and soybean, in some measure because little wheat is grown in Iowa.

The exogenous factors (represented by $v$ in the theory section) employed in our study include soil quality, growing season precipitation, temperature, county geographic location, and distance to crop production center. In what follows, we discuss the construction of these county-level variables and their expected effects on growers' insurance choices.

\section{Soil Quality}

An individual county's soil quality is represented by the percentages of farmland acres under certain Land Capability Classes and sub-classes (LCCs). Land is classified 

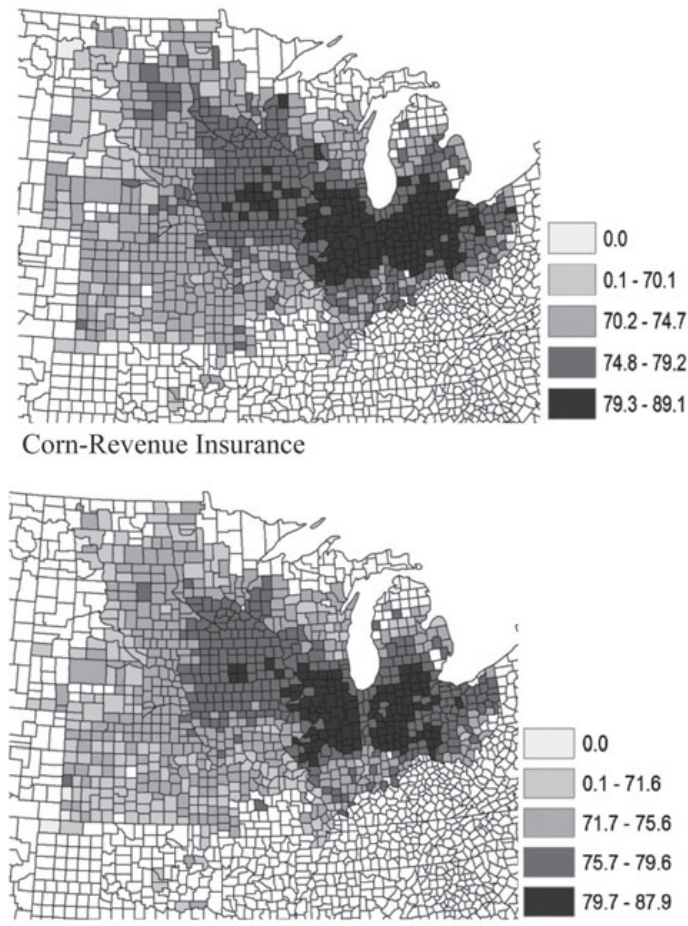

Soybean-Revenue Insurance

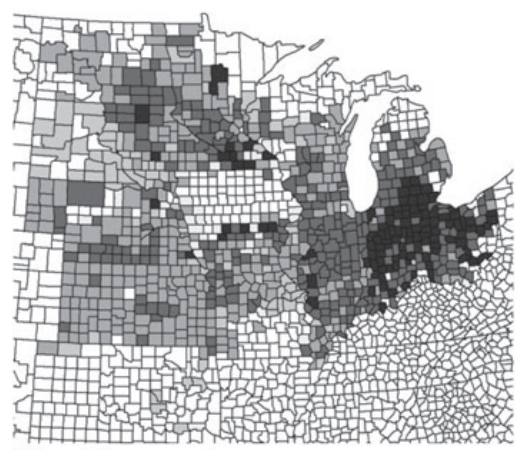

Wheat-Revenue Insurance

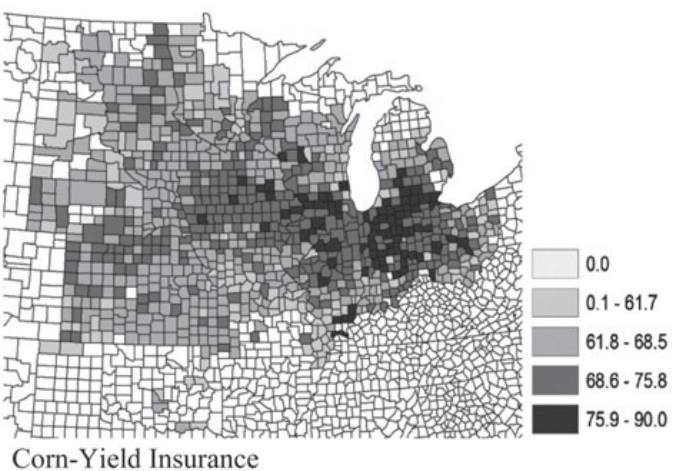

in-Yield Insurance

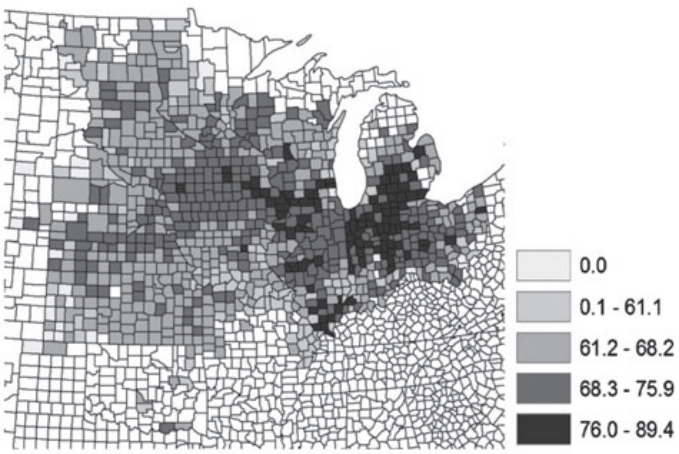

Soybean-Yield Insurance

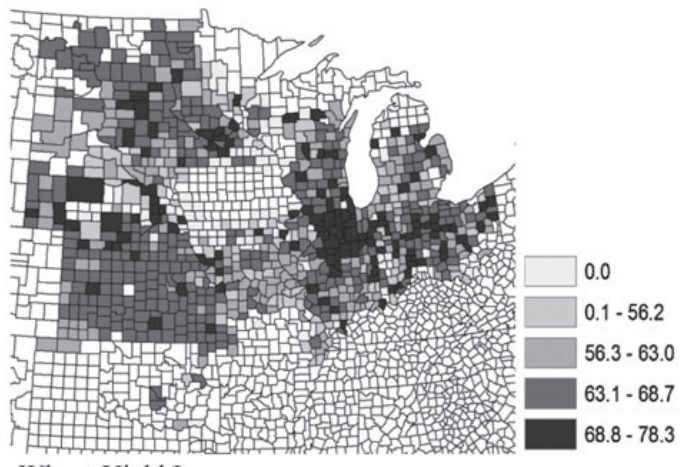

Wheat-Yield Insurance

\section{Figure 5. Acreage weighted revenue/yield insurance coverage levels, 2011}

into eight classes (I to VIII), where classes higher than IV are unsuitable for crop production. We focus on LCC I-IV, where data are obtained from the National Resource Inventory (NRI) database. We aggregate the acres in a given county under LCC I-II and calculate its percentage in the total acreage of LCC I-IV to represent county-level soil quality.

\section{Growing Degree Days and Precipitation}

Following the literature (e.g., Deschênes and Greenstone 2007; Schlenker, Hanemann, and Fisher 2006), growing-degree-days (GDD) is defined as the sum of degrees between lower and upper thresholds (labeled as $T_{l}$ and $T_{h}$, respectively) during the growing season. Thus, the variable is $\min \left[\max \left(T-T_{l}, 0\right), T_{h}\right]$ summed over growing season days. The thresholds are $8^{\circ} \mathrm{C}$ and $32^{\circ} \mathrm{C}$ for corn and soybeans, and $0^{\circ} \mathrm{C}$ and $25^{\circ} \mathrm{C}$ for wheat. AprilSeptember is the assumed growing season for corn and soybean, while for wheat it is April-August. The GDD is then calculated as the county-level average growing degree days over the 31-year period of $1975-2005 .^{10}$ We used the dataset developed in Schlenker

\footnotetext{
${ }^{10}$ To check for robustness we also include the squared term of GDD (GDD^). The results, reported in the supplemental
} 
and Roberts (2009) for our calculations. ${ }^{11}$ In addition, temperatures above $34^{\circ} \mathrm{C}$ are considered to be harmful (Schlenker, Hanemann, and Fisher 2006). ${ }^{12}$ Variable GDD34 is constructed to capture the effect of overheating on yields and is calculated as the county average growing degree days above $34^{\circ} \mathrm{C}$ from 1975-2005.

The precipitation variable denoted by Prec is constructed as average growing season precipitation for each sample county from 1975-2005. Schlenker and Roberts' (2009) dataset is also employed in this calculation. ${ }^{13}$ We caution the reader that how climate impacts yields is determined in part by other geographic considerations, as well as by choice of crop variety. For example, soils vary geographically and the climate that best complements one soil type may not be optimal on another soil type, so that yield riskiness depends on climate-soil interactions.

\section{Location}

We represent a county's geographic location by the $\mathrm{x}$ and $\mathrm{y}$ coordinates of the county centroid (X-loc and Y-loc). County spatial data are downloaded from the Ersi website maintained by the U.S. Census Bureau. ${ }^{14}$ On the one hand, county location is likely to correlate strongly with climate and soil quality. For example, high X-loc (i.e., further east) is probably associated with increasing precipitation and thus obscures the effect of precipitation, while high Y-loc (i.e., further north) is probably linked with decreasing GDD. On the other hand, location variables could potentially capture non-climate features that are not fully accounted for in the climate variables including, for example, distance to market and infrastructure availability. These location variables are used as robustness checks.

materials online, do not identify a substantive impact on our findings.

${ }^{11}$ Dataset and detailed description available at http://www. columbia.edu/ $\sim$ ws $2162 /$ dailyData/.

12 The over-heat threshold is considered to be the same for corn, soybean, and wheat.

${ }^{13}$ To check for robustness, we replace the precipitation variable with the Palmer Z index for the months of May, June, July, August, and September, as well as the squares of these variables. The variable explanation and regression results are reported in the supplemental materials online, and do not identify a substantive impact on our findings.

${ }^{14}$ See ftp://ftp.igsb.uiowa.edu/gis_library/USA/us_counties.htm (last accessed 1/31/2013).

\section{Distance to Crop Production Center}

Barnett and Coble (2012) suggest that crops grown toward the center of production are less risky for revenue insurance because price-yield correlation is more negative than elsewhere, and Coble (2007) provides supporting evidence. We include a variable to represent distance from crop production center to shed light on its role in contract choice, as posited in propositions 3 through 5 .

The production center for crop $i \in\{$ corn, soybean, wheat $\},\left(\hat{x}_{i}, \hat{y}_{i}\right)$ is solved as the "center of mass", that is, $\min _{\left(\hat{x}_{i}, \hat{y}_{i}\right)} \sum_{j}$ $\operatorname{Prod}_{j, i} \times\left[\left(x_{j}-\hat{x}_{i}\right)^{2}+\left(y_{j}-\hat{y}_{i}\right)^{2}\right]$, where $\operatorname{Prod}_{j, i}$ denotes crop $i$ 's production in county $j$ in 2011, and $\left(x_{j}, y_{j}\right)$ denotes the geographic location of county $j .{ }^{15}$ The resulting production centers for five recent years are presented in figure 6 , and the distance measures are then calculated accordingly. The production centers for corn and soybeans did not shift far, and all are in Southeast Iowa, a reasonable general location given that the central Corn Belt stretches east-southeast from northwest Iowa to western Indiana. The 2008 estimate for wheat moved further southeast and is less satisfactory, being in central Nebraska, where irrigated corn dominates wheat production. Furthermore, whereas U.S. corn and soybean crops are comparatively homogeneous in physical characteristics as well as sowing and harvesting dates, wheat grown to the north of our identified center is typically hard red spring wheat, while to the south it is hard red winter wheat, and to the east it is soft red wheat.

\section{Empirical Analysis}

The empirical analysis is divided into two parts. The first establishes whether the production relations underpinning proposition 2 apply. Thus, an empirical test for logconcavity of $J(\psi)$, that is, $G(\psi) / \int_{\underline{\varepsilon}}^{\psi} G(\varepsilon) d \varepsilon$ decreasing, is conducted. In addition, we test for whether the yield coefficient of variation is monotone in each of several exogenous geographic factors. The second empirical portion determines whether the implication in proposition 2 applies. Thus, we establish the

\footnotetext{
15 For wheat, 2008 is the most recent year when NASS production data are available, so we use 2008 data instead of 2011 data to calculate wheat's production center.
} 


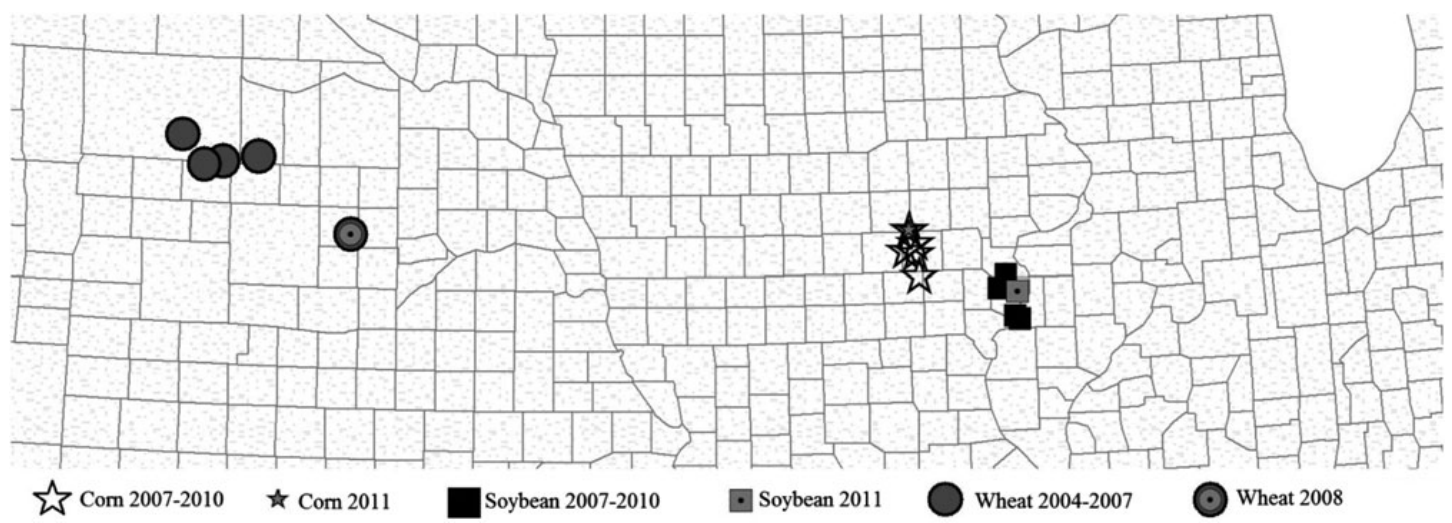

Figure 6. Production centers for corn, soybean, and wheat based on production

relationship between crop insurance choices and the same exogenous factors.

\section{Empirical Tests for Monotonic Coefficients of Variation and for Log Concavity}

Log-concavity of $J(\psi)$ is essential to our hypothesis. We conduct the empirical test in two steps: $i$ ) we run a Just-Pope type regression on exogenous factors $v$; and $i i)$ we use the location and scale normalized yield distributions to test for log-concavity of $J(\psi)$.

Assume that crop producers face the JustPope technology as specified in equation (1), where the mean and variance of crop yield $y_{i}, i \in\{$ corn, soybean, wheat $\}$, is determined by the exogenous factors $v$, including LCC, GDD, GDD34, Prec, and X/Y-loc. The mean equation, $\mu(v)$, and variance equation, $\sigma(v)$, are estimated in three steps. These are: $(i)$ we run the OLS regression $y_{i}=v_{i} \beta_{1}+u_{1}$, which yields consistent estimator $\hat{\beta}_{1}$ and corresponding residual term $\hat{u}_{1}$, where the $v_{i}$ are county-level exogenous factors for crop $i$, and the $y_{i}$ are farm-level yield observations; (ii) we run the OLS regression $\left(\hat{u}_{1}\right)^{2}=v_{i} \gamma+u_{2}$ and generate consistent estimator $\hat{\gamma}$; (iii) we use weighted least squares (WLS) to reestimate the mean equation $y_{i}^{\prime}=v_{i}^{\prime} \beta_{2}+u_{3}$, where $y^{\prime}=y / \sqrt{v_{i} \hat{\gamma}}$ and $v^{\prime}=v / \sqrt{v_{i} \hat{\gamma}}$. The WLS is used to correct for heteroskedasticity in $u_{1}$.

For our study, unit-level corn, soybean, and wheat yield data in the sample states between 1990-2009 are obtained from RMA/USDA. The RMA yield data contain up to 10 years of yield history for crops on each insured unit under the federal crop insurance program, which can be single or multiple fields on a farm. We restrict our sample to all units with
10 years of yield records. ${ }^{16}$ Following the multiplicative model described in Claassen and Just (2011), ${ }^{17}$ unit level yields are detrended using the county-level yield data from 1960 to 2009, as downloaded from a USDA National Agricultural Statistics Service (NASS) database. We then adjust all de-trended historical data to the 2009 yield by adding back the county-level trend yield and adjusting for unit-specific productivity. We control for irrigation effects by considering only non-irrigated farmland. We utilized $4,007,335$ observations for corn, 3,888,556 for soybean, and 2,284,055 for wheat.

Estimation results for $\hat{\beta}_{2}$ and $\hat{\gamma}$ for corn, soybean, and wheat are included in the supplemental materials available online. Growing degree days increase mean yields when location controls are not included, but the effect on yield variance is less clear. The overheating temperature is harmful across all crops, and when location controls are not included, excess growing degree days decrease the yield variance. Precipitation increases mean yield, decreases yield variance for corn and wheat, but appears to increase variance for soybeans. The results indicate that the impact of county location is

\footnotetext{
16 Selection bias is a potential concern in the tests for logconcavity. Upon being limited to a 10-year yield history, our sample represents about one-third of all records. However, there is no clear remedy for the problem. Over $20 \%$ of the records would be screened out even if we required a yield history length of just 1 year. The number of records increase uniformly as we decrease history length toward one year so that we do not gain much for each year we move below 10. On the other hand, our confidence in the quality of the detrending process we apply falls as history length declines.

17 Interested readers are referred to eqns. (1), and (2')-(4') in Claassen and Just (2011).
} 
Table 3. Estimation Results for the Coefficient of Variation for Yield Trends

\begin{tabular}{lccc}
\hline & Corn & Soybean & Wheat \\
\hline LCC & $-0.002^{\mathrm{a}}$ & $-0.001^{\mathrm{a}}$ & $-0.001^{\mathrm{a}}$ \\
GDD & $-0.0001^{\mathrm{a}}$ & $-0.0001^{\mathrm{a}}$ & $0.0001^{\mathrm{a}}$ \\
GDD34 & $0.01^{\mathrm{a}}$ & $0.01^{\mathrm{a}}$ & $0.005^{\mathrm{a}}$ \\
Prec & $-0.006^{\mathrm{a}}$ & 0.0004 & $-0.004^{\mathrm{a}}$ \\
Constant & $0.92^{\mathrm{a}}$ & $0.43^{\mathrm{a}}$ & $0.35^{\mathrm{a}}$ \\
\hline Adj. $R^{2}$ & 0.88 & 0.96 & 0.97 \\
\hline
\end{tabular}

Note: Superscript a denotes significance at the 0.01 level.

significantly intertwined with those of temperature and precipitation, especially for soybean and wheat.

Table 3 reports the results when coefficient of variation $\tau$ is regressed on the exogenous factors in $v$, where $\tau$ is calculated for each county individually based on crop yield data. For all three crops, $\tau$ increases with an increase in overheating (i.e., GDD34) and decreases with an increase in land quality. For corn and soybeans $\tau$ decreases with an increase in GDD, while for corn and wheat it decreases with an increase in precipitation. Thus, 10 of 12 responses involve $\tau$ decreasing when growing conditions improve, and all of these responses are significant at the 0.01 level. ${ }^{18}$ Figure 7 illustrates the coefficients of variation for corn, soybean, and wheat yields that are arrived at using the Just-Pope estimation results without location variables included. The western Great Plains generally has the largest values.

Given the estimated technology parameters, we obtain location and scalenormalized yields as $y^{e}=\left(y-\hat{\beta}_{2} v\right) / \sqrt{v \hat{\gamma}}$. Similarly, the value of $\psi^{e}$ is calculated as $\psi^{e}=(\phi-1)\left(\hat{\beta}_{2} v\right) /(v \hat{\gamma})$. Given the large sample size, we quantify the Cumulative Distribution Function (CDF) for $y^{e}$ numerically using non-parametric methods. ${ }^{19}$ The value of $G(\varepsilon)$ is then linearly interpolated from the estimated empirical $\mathrm{CDF}^{20}$ Integral $\int_{\varepsilon}^{\psi} G(\varepsilon) d \varepsilon$ is evaluated using standard Riemann sum approximation (Robert and

18 To save space, the results with location variables are included in the supplemental materials online. For these, in each case better growing conditions reduce the yield coefficient of variation, although three responses are not significant at the 0.01 level.

${ }^{19}$ This is implemented using the ecdf(.) function in Matlab, which calculates the Kaplan-Meier estimate of the CDF, also known as the empirical CDF. Readers are referred to Cox and Oakes (1984) for more details.

20 The Matlab function interp1(.) is employed for implementation.
Casella 2004). Figure 8 presents the numerically evaluated curves $G(\psi) / \int_{\varepsilon}^{\psi} G(\varepsilon) d \varepsilon$ for corn, soybean, and wheat when $\phi=0.75 .{ }^{21}$ For other values of $\phi$ they are almost identical. Clearly, $G(\psi) / \int_{\underline{\varepsilon}}^{\psi} G(\varepsilon) d \varepsilon$ decreases in $\psi$, and thus $J(\psi)$ is log-concave. The conditions underpinning proposition 2 therefore apply. ${ }^{22}$

\section{Analysis of Insurance Contract Choices}

We must still establish whether the inferences drawn from propositions 1 through 5 are supported by the data. A linear regression model is employed to determine how insurance contract choices vary with exogenous factors $v$ to test the hypothesis in proposition 2 . First, we analyze the county-level acreage share of different coverage levels $\left(C L_{j}\right)$ under revenue and yield insurance contracts, $s_{j}^{R}\left(s_{j}^{Y}\right)$, for which the acreage is aggregated over the insurance products summarized in table $2 .^{23}$ For coverage levels, we aggregate insurance programs as: $50 \%$ by itself; $55 \%$ with $60 \%$; $65 \%$ with $70 \%$; and then $75 \%$ through $85 \%$ together. Table 1 shows that the subsidy rates for $55 \%$ and $60 \%$ are the same, which makes $60 \%$ attractive relative to $55 \%$, as there is no additional cost to buy-up. Also, some regions have coverage limits in that one cannot buy $80 \%$ or $85 \%$ coverage in certain counties. We apply the logit transformation on the share $s_{j}$ to bound shares within their true domain $[0,1]$, that is, the dependent variable is $\ln \left[s_{j} /\left(1-s_{j}\right)\right]$, and then we use OLS to estimate the parameters. The results are presented in table 4, in which columns I and II exclude and include, respectively, the distance variables. $^{24}$

\footnotetext{
21 Estimates are without the location variables. Simulation results using estimates with location variables are available upon request. The results are essentially the same as those reported here.

22 Similar analyses are conducted for corn, soybean, and wheat revenues. Explanations of crop revenue construction and also estimation results are included in the supplemental materials online. The results indicate that the Just-Pope regression residuals for crop revenues are log-concave and thus proposition 2 also holds for revenues. Patterns of coefficient of variation responses to exogenous factors are largely consistent with, but not as significant as, those for crop yields.

${ }^{23}$ In addition, following a reviewer's suggestion, we regress the acreage-weighted coverage levels (WCL) of individual counties, the construction of which is described in the previous section, on the set of the exogenous factors $v$. The results are included in the supplemental materials online. The estimation results are consistent with what we have discussed.

24 Results with location variables are reported in the supplemental materials online.
} 

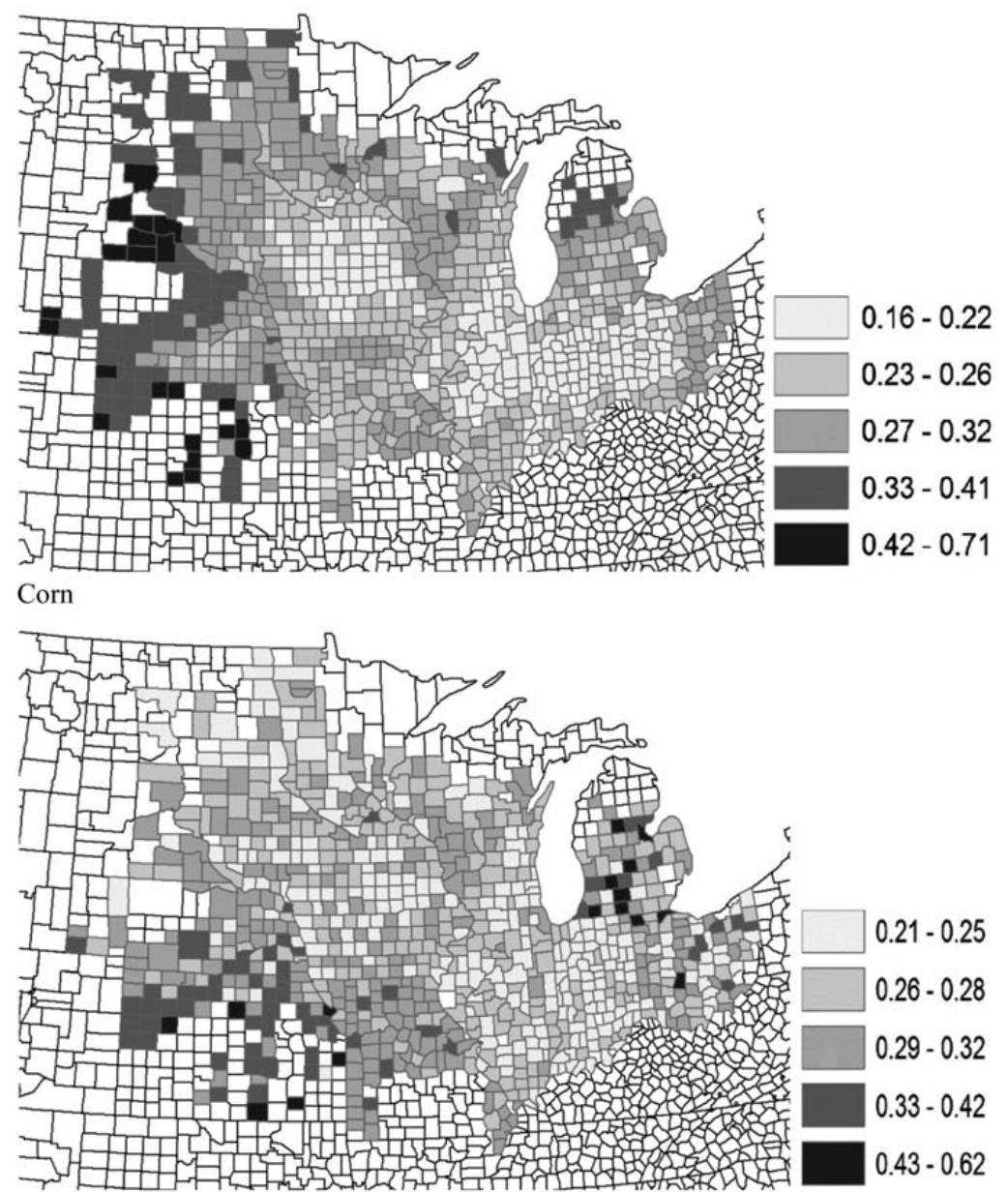
Soybeans

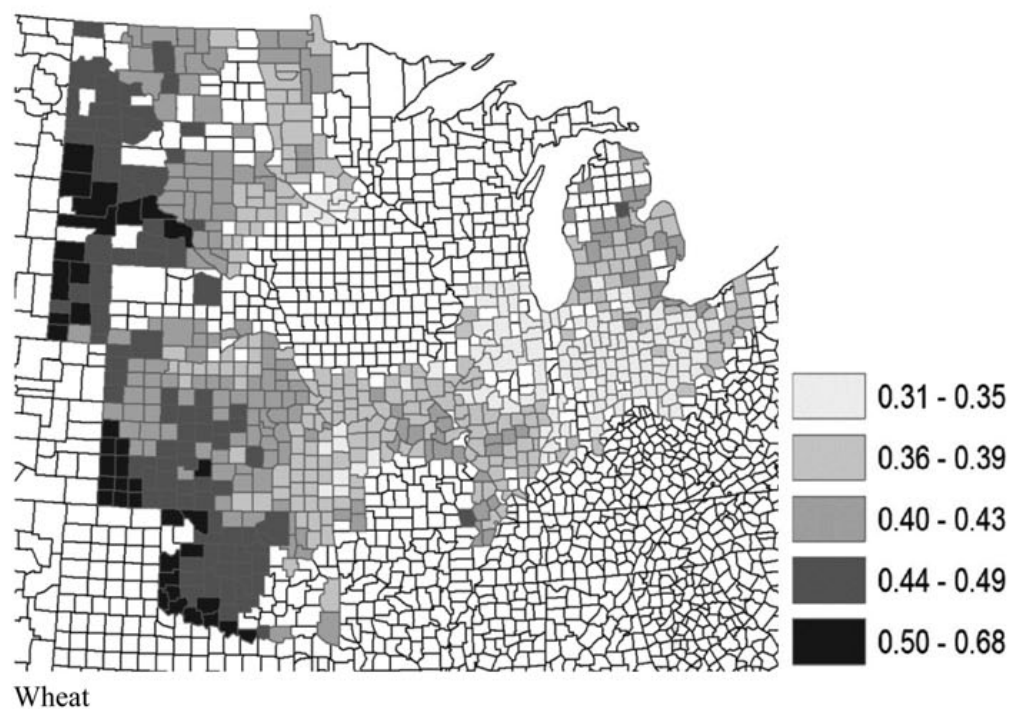

Figure 7. Coefficient of variation for corn, soybean, and wheat yields. 

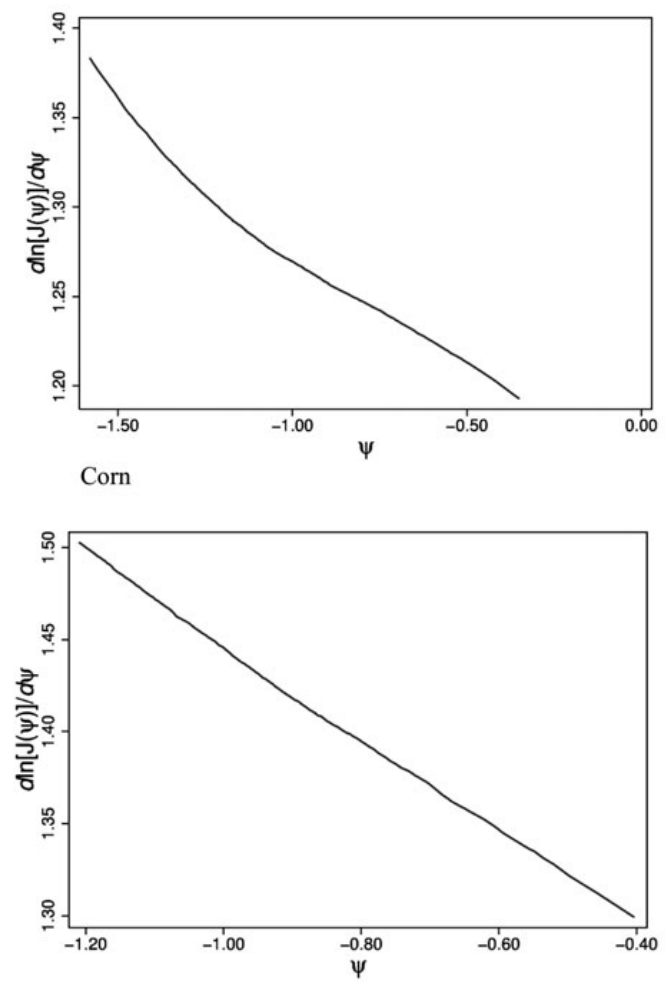

Soybean

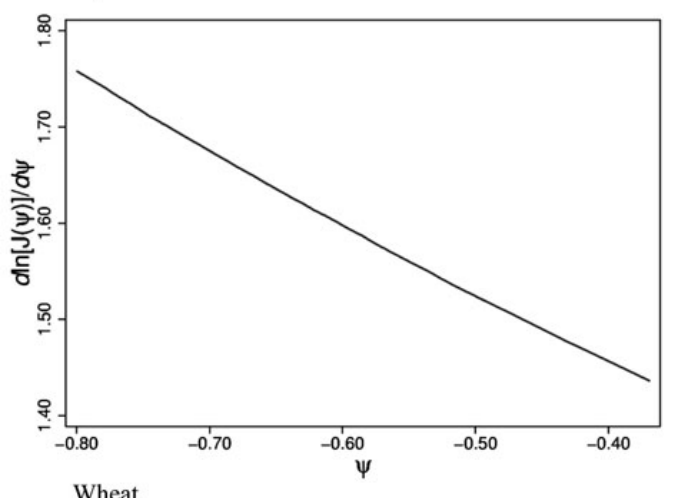

Figure 8. Slope of $\ln [J(\psi)]$ for corn, soybean, and wheat for $\phi=0.75$.

For revenue and yield insurance across crops (corn, soybean, and wheat), we see a consistent pattern associated with soil quality (LCC) and overheat growing days (GDD34). Counties with better soil quality, and also with fewer overheat days during the growing season, are associated with larger shares of high coverage level contracts. In other words, farmers who produce crops on better quality farmland and have favorable weather conditions in the growing season tend to choose insurance products with relatively high coverage levels, which is largely consistent with our hypothesis in proposition 2 . In general, more precipitation also appears to promote higher coverage levels, but the effect of GDD is not so clear.

For corn and soybean, having controlled for land quality and climate, production further away from the production centers tend to use comparatively low (50-70\%) coverage level contracts. These findings are consistent with proposition 5; the pattern is indicated by the estimated coefficients on the distance variable and applies to revenue as well as yield insurance contracts. The pattern does not apply for wheat yield and revenue insurance, where in any case figures 5 and 6 reveal the distance measure to be problematic. ${ }^{25}$

For the choice of revenue versus yield insurance, we construct the dependent variable as the logit transformation of $A_{j}^{R} /\left(A_{j}^{R}+A_{j}^{Y}\right)$, where $A_{j}^{R}$ (resp., $A_{j}^{Y}$ ) represents the acres under revenue (yield) insurance across all available coverage levels in county $j$. The OLS estimation results are reported in table 5. For corn and soybean, specifications I (excluding distance) and II (including distance) both show that better soil quality and low overheating growing days increase revenue insured acre share. ${ }^{26}$ For wheat, land quality does not register as significant, while overheating does not appear to be an issue either. The effect of growing degree days is mixed across crops. Precipitation has no discernible impact on contract category choice for corn and soybeans, but promotes yield insurance in wheat. In general, better growing conditions, with lower risk, tend to favor revenue insurance. This suggests that the revenue expectation bias

\footnotetext{
25 To confirm robustness, we have considered alternative measures of climate variables in the analysis of coverage level choices. These include replacing the pair-growing degree days (GDD) and excess growing degree days with the pair GDD and (GDD mean GDD) ${ }^{2}$. The latter specification is chosen because in that presentation, the coefficient on GDD represents the marginal effect of GDD when evaluated at the mean. We have also replaced precipitation, labeled as Prec, with monthly Palmer's Z indices and their square over the growing months of May, June, July, August, and September. We include the square terms to capture nonlinearities in drought conditions, as a very high Palmer index value can be as harmful as a very low index value. Drought and excess moisture are both threats to yield. Arguably there should be a quadratic Prec term too. But Prec measures the flow of moisture, while the Palmer Z measures stock, so we would view it as more effectively capturing extreme stress situations. The results, presented in the supplemental materials online, are very similar to the results presented here.

${ }^{26}$ Results with location variables are reported in the supplemental materials online.
} 
Table 4. Regression Results of Insurance Contract Choices-Coverage Levels

\begin{tabular}{|c|c|c|c|c|c|c|c|c|}
\hline \multicolumn{9}{|c|}{ Revenue Insurance } \\
\hline \multirow[b]{2}{*}{ Corn } & \multicolumn{4}{|c|}{ I } & \multicolumn{4}{|c|}{ II } \\
\hline & $50 \%$ & $55-60 \%$ & $65-70 \%$ & $75-85 \%$ & $50 \%$ & $55-60 \%$ & $65-70 \%$ & $75-85 \%$ \\
\hline$\overline{\mathrm{LCC}}$ & $-0.02^{\mathrm{c}}$ & $-0.02^{\mathrm{c}}$ & $-0.02^{\mathrm{c}}$ & $0.01^{\mathrm{c}}$ & $-0.02^{\mathrm{c}}$ & $-0.02^{\mathrm{c}}$ & $-0.02^{\mathrm{c}}$ & $0.01^{\mathrm{c}}$ \\
\hline GDD & 0.0005 & -0.0002 & -0.0002 & -0.0002 & 0.0004 & -0.0002 & -0.0002 & -0.0002 \\
\hline GDD34 & 0.01 & $0.06^{\mathrm{c}}$ & $0.12^{\mathrm{c}}$ & $-0.08^{\mathrm{c}}$ & 0.01 & $0.06^{\mathrm{c}}$ & $0.12^{\mathrm{c}}$ & $-0.08^{c}$ \\
\hline Prec & $-0.03^{\mathrm{c}}$ & $-0.03^{\mathrm{c}}$ & $-0.04^{\mathrm{c}}$ & $0.04^{\mathrm{c}}$ & -0.009 & -0.009 & $-0.03^{c}$ & $0.03^{\mathrm{c}}$ \\
\hline Distance & & & & & $0.01^{\mathrm{c}}$ & $0.01^{\mathrm{c}}$ & 0.001 & $-0.005^{\mathrm{c}}$ \\
\hline Constant & $-2.91^{\mathrm{c}}$ & $-2.02^{\mathrm{c}}$ & $1.89^{\mathrm{c}}$ & $-1.51^{\mathrm{c}}$ & $-3.30^{\mathrm{c}}$ & $-2.31^{\mathrm{c}}$ & $1.85^{\mathrm{c}}$ & $-1.42^{\mathrm{c}}$ \\
\hline Adj. $R^{2}$ & 0.14 & 0.16 & 0.40 & 0.37 & 0.16 & 0.18 & 0.40 & 0.38 \\
\hline & 639 & 737 & 927 & 918 & 639 & 737 & 927 & 918 \\
\hline \multicolumn{9}{|l|}{ Soybean } \\
\hline LCC & $-0.02^{\mathrm{c}}$ & $-0.02^{\mathrm{c}}$ & $-0.02^{\mathrm{c}}$ & $0.01^{\mathrm{c}}$ & $-0.02^{\mathrm{c}}$ & $-0.02^{\mathrm{c}}$ & $-0.02^{\mathrm{c}}$ & $0.01^{\mathrm{c}}$ \\
\hline GDD & $0.002^{c}$ & $0.0008^{\mathrm{c}}$ & 0.0002 & $-0.0008^{c}$ & $0.002^{\mathrm{c}}$ & $0.001^{\mathrm{c}}$ & $0.0004^{\mathrm{a}}$ & $-0.0009^{\mathrm{c}}$ \\
\hline GDD34 & $-0.06^{\mathrm{c}}$ & $0.04^{\mathrm{c}}$ & $0.11^{\mathrm{c}}$ & $-0.07^{\mathrm{c}}$ & $-0.05^{\mathrm{b}}$ & $0.03^{\mathrm{b}}$ & $0.10^{\mathrm{c}}$ & $-0.06^{\mathrm{c}}$ \\
\hline Prec & $-0.03^{\mathrm{b}}$ & $-0.03^{\mathrm{c}}$ & $-0.05^{\mathrm{c}}$ & $0.05^{\mathrm{c}}$ & $-0.04^{\mathrm{c}}$ & -0.02 & $-0.03^{\mathrm{c}}$ & $0.04^{\mathrm{c}}$ \\
\hline Distance & & & & & -0.006 & $0.008^{\mathrm{b}}$ & $0.01^{\mathrm{c}}$ & $-0.007^{\mathrm{c}}$ \\
\hline Constant & $-6.21^{\mathrm{c}}$ & $-4.06^{\mathrm{c}}$ & $1.69^{\mathrm{c}}$ & $-0.84^{\mathrm{c}}$ & $-5.85^{\mathrm{c}}$ & $-4.59^{c}$ & $1.04^{\mathrm{c}}$ & -0.42 \\
\hline Adj. $R^{2}$ & 0.11 & 0.15 & 0.43 & 0.39 & 0.11 & 0.16 & 0.44 & 0.40 \\
\hline obs. & 578 & 666 & 897 & 895 & 578 & 666 & 897 & 895 \\
\hline \multicolumn{9}{|l|}{ Wheat } \\
\hline LCC & $-0.01^{\mathrm{c}}$ & $-0.01^{\mathrm{c}}$ & $-0.01^{\mathrm{c}}$ & $0.01^{\mathrm{c}}$ & $-0.01^{\mathrm{c}}$ & $-0.01^{\mathrm{c}}$ & $-0.009^{c}$ & $0.01^{\mathrm{c}}$ \\
\hline GDD & 0.0002 & -0.00005 & $-0.0005^{\mathrm{a}}$ & 0.0001 & 0.0002 & -0.00006 & $-0.0006^{\mathrm{c}}$ & 0.0003 \\
\hline GDD34 & $-0.07^{\mathrm{c}}$ & -0.01 & $0.10^{\mathrm{c}}$ & $-0.09^{c}$ & $-0.09^{c}$ & -0.03 & $0.06^{\mathrm{c}}$ & $-0.05^{\mathrm{c}}$ \\
\hline Prec & $0.03^{b}$ & 0.008 & $-0.02^{\mathrm{c}}$ & $0.04^{\mathrm{c}}$ & $0.03^{\mathrm{c}}$ & 0.01 & -0.001 & $0.02^{\mathrm{c}}$ \\
\hline Distance & & & & & $-0.009^{c}$ & $-0.006^{\mathrm{b}}$ & $-0.02^{\mathrm{c}}$ & $0.02^{\mathrm{c}}$ \\
\hline Constant & $-4.44^{\mathrm{c}}$ & $-3.14^{\mathrm{c}}$ & $1.91^{\mathrm{c}}$ & $-2.96^{\mathrm{c}}$ & $-5.33^{c}$ & $-3.74^{\mathrm{c}}$ & -0.39 & $-1.55^{\mathrm{c}}$ \\
\hline Adj. $R^{2}$ & 0.16 & 0.03 & 0.26 & 0.28 & 0.18 & 0.04 & 0.38 & 0.37 \\
\hline obs. & 393 & 450 & 735 & 730 & 393 & 450 & 735 & 730 \\
\hline
\end{tabular}

Yield Insurance

I

II

\begin{tabular}{|c|c|c|c|c|c|c|c|c|}
\hline Corn & $50 \%$ & $55-60 \%$ & $65-70 \%$ & $75-85 \%$ & $50 \%$ & $55-60 \%$ & $65-70 \%$ & $75-85 \%$ \\
\hline LCC & $-0.01^{\mathrm{c}}$ & $-0.01^{\mathrm{c}}$ & $-0.006^{\mathrm{c}}$ & $0.01^{\mathrm{c}}$ & $-0.01^{\mathrm{c}}$ & $-0.01^{\mathrm{c}}$ & $-0.006^{\mathrm{c}}$ & $0.01^{\mathrm{c}}$ \\
\hline GDD & $0.0005^{\mathrm{a}}$ & 0.00006 & $-0.001^{\mathrm{c}}$ & $0.001^{\mathrm{c}}$ & 0.0004 & -0.00005 & $-0.001^{\mathrm{c}}$ & $0.001^{\mathrm{c}}$ \\
\hline GDD34 & $-0.03^{\mathrm{b}}$ & -0.0005 & $0.13^{\mathrm{c}}$ & $-0.13^{c}$ & $-0.03^{\mathrm{a}}$ & 0.002 & $0.13^{\mathrm{c}}$ & $-0.13^{\mathrm{c}}$ \\
\hline Prec & $-0.02^{\mathrm{c}}$ & -0.008 & 0.004 & -0.006 & 0.003 & $0.02^{\mathrm{b}}$ & -0.005 & $-0.02^{b}$ \\
\hline Distance & & & & & $0.01^{\mathrm{c}}$ & $0.02^{\mathrm{c}}$ & $-0.006^{\mathrm{b}}$ & $-0.008^{\mathrm{c}}$ \\
\hline Constant & $-1.14^{\mathrm{c}}$ & $-1.69^{c}$ & $1.74^{\mathrm{c}}$ & $-3.91^{\mathrm{c}}$ & $-1.50^{\mathrm{c}}$ & $-2.21^{\mathrm{c}}$ & $1.88^{\mathrm{c}}$ & $-3.73^{c}$ \\
\hline Adj. $R^{2}$ & 0.06 & 0.03 & 0.16 & 0.18 & 0.09 & 0.08 & 0.17 & 0.18 \\
\hline obs. & 780 & 668 & 886 & 761 & 780 & 668 & 886 & 761 \\
\hline
\end{tabular}

Soybean

\begin{tabular}{lrlllrrrr}
\hline LCC & $-0.02^{\mathrm{c}}$ & $-0.01^{\mathrm{c}}$ & $-0.009^{\mathrm{c}}$ & $0.02^{\mathrm{c}}$ & $-0.02^{\mathrm{c}}$ & $-0.01^{\mathrm{c}}$ & $-0.009^{\mathrm{c}}$ & $0.02^{\mathrm{c}}$ \\
GDD & $0.002^{\mathrm{c}}$ & -0.00008 & $-0.002^{\mathrm{c}}$ & $-0.001^{\mathrm{c}}$ & $0.002^{\mathrm{c}}$ & 0.0002 & $-0.001^{\mathrm{c}}$ & $-0.001^{\mathrm{c}}$ \\
\hline
\end{tabular}


Table 4. Continued

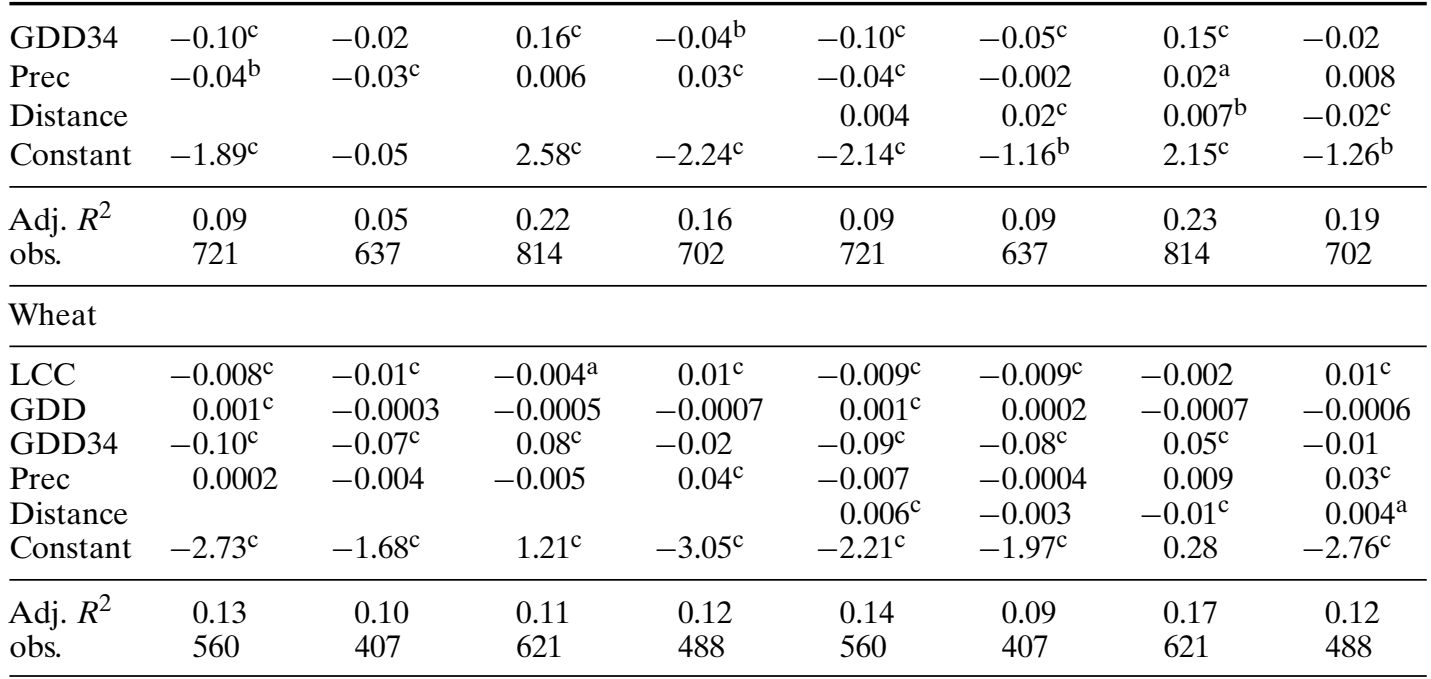

Note: Superscripts a, b, and c denote significance at the $0.10,0.05$, and 0.01 levels, respectively.

Table 5. Regression Results for Revenue versus Yield Insurance (Share of Total Contracts That Are Revenue)

\begin{tabular}{|c|c|c|c|c|c|c|}
\hline & \multicolumn{2}{|c|}{ Corn } & \multicolumn{2}{|c|}{ Soybean } & \multicolumn{2}{|c|}{ Wheat } \\
\hline & I & II & I & II & I & II \\
\hline $\mathrm{LCC}$ & $0.01^{\mathrm{c}}$ & $0.01^{\mathrm{c}}$ & $0.005^{\mathrm{c}}$ & $0.005^{\mathrm{c}}$ & -0.00004 & 0.00009 \\
\hline GDD & $0.0007^{\mathrm{c}}$ & $0.0007^{c}$ & $-0.0004^{b}$ & $-0.0004^{b}$ & 0.00009 & 0.00009 \\
\hline GDD34 & $-0.04^{\mathrm{c}}$ & $-0.04^{\mathrm{c}}$ & $-0.03^{\mathrm{c}}$ & $-0.03^{c}$ & 0.01 & 0.01 \\
\hline Prec & 0.007 & -0.007 & -0.007 & -0.006 & $-0.05^{\mathrm{c}}$ & $-0.05^{\mathrm{c}}$ \\
\hline Distance & & $-0.009^{c}$ & & 0.0007 & & -0.0008 \\
\hline Constant & 0.52 & $0.69^{\mathrm{b}}$ & $3.61^{\mathrm{c}}$ & $3.57^{\mathrm{c}}$ & $3.95^{\mathrm{c}}$ & $3.88^{\mathrm{c}}$ \\
\hline Adj. $R^{2}$ & 0.10 & 0.12 & 0.10 & 0.10 & 0.15 & 0.14 \\
\hline obs. & 929 & 929 & 885 & 885 & 756 & 756 \\
\hline
\end{tabular}

Note: Superscripts a, b, and c denote significance at the $0.10,0.05$, and 0.01 levels, respectively.

effect in revenue insurance product design dominates the risk effect.

For corn, the distance variable indicates a negative effect. For wheat and soybean the distance effect is not significant. For corn, but not for the other two crops, proximity to the center of a crop's production, where the price-yield correlation is more negative, appears to increase demand for revenue insurance. This is consistent with the idea that the expected revenue formation bias dominates the "natural hedge" effect as laid out in propositions 3 and 4 .

As a robustness check, we construct revenue (or yield) insured acres as a share of total planted acres in individual counties where the planted acreage data are downloaded from the NASS/USDA website. Results are reported in the supplemental materials available online. Basically, for corn and soybeans better exogenous soil and weather conditions generally discourage yield insurance as a share of planted acres, but the effect on encouraging revenue insurance is not so clear. For corn, distance from the production center promotes yield insurance as a share of planted acres, but reduces revenue insurance.

Our second robustness check focuses on the so-called area/group insurance, which is different from the individual farm insurance policies because it is triggered by a county yield index instead of by farm yield. In our sample GRP, GRIP, and GRIPH plans fall 
into the group insurance category and were not distinguished from other insurance products in the analyses to this point. We calculate the share of acres under area and revenue (or yield) insurance in total insured acres and use them as the dependent variables. The OLS regression results are also presented in the supplemental materials online. The results corroborate our findings on revenue versus yield insurance choices in that when soil and climate conditions are more favorable, then farmers tend to favor revenue insurance products over yield insurance products, and more centrally located growers favor area revenue insurance over area yield insurance.

\section{Conclusion}

We develop a theoretical framework regarding geographic regularities in crop insurance contract choices, and then we test Risk Management Agency data for the inferences drawn. The framework provides simple and testable hypotheses, while statistical tests provide strong support for these hypotheses.

For corn, soybean, and wheat, the results indicate that: $(i)$ farmers producing crops on better quality farmland and under favorable weather conditions are more likely to choose insurance contracts with higher coverage levels ( $75 \%$ or higher); (ii) similarly, the share of land classified as LCC I or II and experiencing less harmful overheat growing days are strongly associated with choices of revenue insurance products. The results are robust to the inclusion of a variable to account for distance to a crop's center of production. We also suggest that an improper approach to forming expected revenue may affect the choice between revenue and yield insurance contracts, and may at least partially explain why more centrally located growers prefer revenue insurance when the presence of a natural hedge would suggest a comparative preference for yield insurance.

In the United States, the growth of and heterogeneity in subsidy transfers across different crops, contracts and regions, as well as the level of government budget outlays entailed, and the growing government debt stress all suggest the need for further analysis of these markets to assist policy-makers. Were finer geographic detail in the form of relating farm-level yield performance to farm-level characteristics ever available in abundance, it could provide more clarity on the demand for different crop insurance contracts. Another possible line of inquiry is to consider how differential subsidies for enterprise units, when compared with basic and optional crop insurance units, have affected demand and budget outlays.

The data we have considered may also allow for a more general understanding of demand for insurance. A large body of literature exists that documents anomalous risk management choices (see DellaVigna (2009) for a review). Some of these anomalies concern how the temporal evolution of risk realizations affects demand. By contrast with many insured risks, crop yield risks originate largely in weather events and location-specific daily records on these events are widely available. One possibility is to compare year-to-year changes in demand for crop insurance with weather realizations to assess whether growers respond rationally to risk.

\section{References}

Babcock, B.A. 2011. Time to Revisit Crop Insurance Premium Subsidies? CARD Policy Brief 11-PB 4. Center for Agricultural and Rural Development, Iowa State University.

Bagnoli, M., and T. Bergstrom. 2005. Logconcave Probability and its Applications. Economic Theory 26 (2): 445-469.

Barnett, B., and K.H. Coble. 2012. Understanding Regional Differences in Farm Policy Preferences. American Journal of Agricultural Economics 94 (2): 528-534.

Briggeman, B.C. 2011. The Importance of Off-Farm Income to Servicing Farm Debt. Federal Reserve Bank of Kansas City. Economic Review (First Quarter): 63-82.

Claassen, R., F. Carriazo, J.C. Cooper, D. Hellerstein, and K. Udea. 2011. Grassland to Cropland Conversion in the Northern Plains: The Role of Crop Insurance, Commodity, and Disaster Programs. Washington, DC: U.S. Department of Agriculture, Economic Research Service, ERR-120. http://www.ers.usda.gov/ media/128019/err120.pdf.

Claassen, R., and R.E. Just. 2011. Heterogeneity and Distributional Form of Farm Yields. American Journal of Agricultural Economics 93 (1): 144-160. 
Coble, K.H. 2007. Federal Crop Insurance and Farm Programs: Will WTO or Budget Concerns Shape the Debate? Paper presented at 2007 Agricultural Outlook Forum, Arlington VA.

Coble, K.H., T.O. Knight, B.K. Goodwin, M.F. Miller, and R.M. Rejesus. 2010. A Comprehensive Review of the RMA APH and $C O M B O$ Rating Methodology, Final Report. Washington, DC: U.S. Dept. of Agriculture, Risk Management Agency. http://www.rma.usda.gov/pubs/2009/ comprehensivereview.pdf

Congressional Budget Office. 2012. CBO March 2012 Baseline for Farm Programs. March 13. http://www.cbo.gov/sites/ default/files/cbofiles/attachments/43053 USDAMandatoryFarmPrograms.pdf.

Cox, D.R., and D. Oakes. 1984. Analysis of Survival Data. London: Chapman \& Hall.

Deaton, A., and G. Laroque. 1992. On the Behavior of Commodity Prices. Review of Economic Studies 59 (1): 1-23.

DellaVigna, S. 2009. Psychology and Economics: Evidence from the Field. Journal of Economic Literature 47 (2): 315-372.

Deschênes, O., and M. Greenstone. 2007. The Economic Impacts of Climate Change: Evidence from Agricultural Output and Random Fluctuations in Weather. American Economic Review 97 (1): 354-385.

Edwards, W.M. 2011. Managing Risk with Crop Insurance. Iowa State University Extension, FM-1853, February.

- 2012. Proven Yields and Insurance Units for Crop Insurance. Iowa State University Extension, FM-1860, March.

Glauber, J.W. 2013. The Growth of the Federal Crop Insurance Program, 1990-2011. American Journal of Agricultural Economics 95 (2): 482-488.

Goodwin, B.K. 2001. Problems with Market Insurance in Agriculture. American Journal of Agricultural Economics 83 (3): 643-649.

Hennessy, D.A. 2002. Substitution Between Revenue Futures and Price Futures
Contracts: A Note. Journal of Futures Markets 22 (4): 387-391.

Hennessy, D.A., B.A. Babcock, and D.J. Hayes. 1997. Budgetary and Producer Welfare Effects of Revenue Insurance. American Journal of Agricultural Economics 79 (3): 1024-1034.

Just, R.E., and R.D. Pope. 1979. Production Function Estimation and Related Risk Considerations. American Journal of Agricultural Economics 61 (2): 277-284.

Robert, C.P., and G. Casella. 2004. Monte Carlo Statistical Methods, 2nd Edition. New York: Springer.

Schlenker, W., M.W. Hanemann, and A.C. Fisher. 2006. The Impact of Global Warming on U.S. Agriculture: An Econometric Analysis of Optimal Growing Conditions. Review of Economics and Statistics 88 (1): 113-125.

Schlenker, W., and M.J. Roberts. 2009. Nonlinear Temperature Effects Indicate Severe Damages to U.S. Crop Yields under Climate Change. Proceedings of the National Academy of Sciences 106 (37): 15594-15598.

Shaked, M., and J.G. Shanthikumar. 2007. Stochastic Orders. New York: Springer.

Sherrick, B.J., P.J. Barry, P.N. Ellinger, and G.D. Schnitkey. 2004. Factors Influencing Farmers' Crop Insurance Decisions. American Journal of Agricultural Economics 86 (1): 103-114.

Shields, D.A. 2010. Federal Crop Insurance: Background and Issues. Congressional Research Service, 7-5700.

Smith, V.H., and A.E. Baquet. 1996. The Demand for Multiple Peril Crop Insurance: Evidence from Montana Wheat Farms? American Journal of Agricultural Economics 78 (1): 189-201.

Sumner, D.A., and C. Zulauf. 2012. Economic \& Environmental Effects of Agricultural Insurance Programs. The Council on Food, Agricultural, \& Resource Economics, July.

U.S. Department of Agriculture, Risk Management Agency. 2012. Summary of Business. 
lowa State University does not discriminate on the basis of race, color, age, religion, national origin, sexual orientation, gender identity, genetic information, sex, marital status, disability, or status as a U.S. veteran. Inquiries can be directed to the Director of Equal Opportunity and Compliance, 3280 Beardshear Hall, (515) 294-7612. 